\title{
DRESSING DOWN MIGRANT SEX WORK: THE GLOBAL ANTI-TRAFFICKING REGIME, LEGAL EMPLOYMENT RIGHTS, AND CANADA'S TEMPORARY FOREIGN WORKER PROGRAM
}

\author{
by \\ Vasti Montiel \\ Honours Bachelor of Social Science in International Studies and Modern Languages, \\ University of Ottawa, 2013
}

\author{
A Major Research Paper \\ presented to Ryerson University \\ in partial fulfillment of the requirements for the degree of \\ Master of Arts \\ in the Program of \\ Immigration and Settlement Studies
}

Toronto, Ontario, Canada, 2016

(C) Vasti Montiel 2016 


\section{AUTHOR'S DECLARATION FOR ELECTRONIC SUBMISSION OF A MAJOR RESAERCH PAPER (MRP)}

I hereby declare that I am the sole author of this Major Research Paper. This is a true copy of the MRP, including any required final revisions, as accepted by my examiners.

I authorize Ryerson University to lend this MRP to other institutions or individuals for the purpose of scholarly research.

I further authorize Ryerson University to reproduce this MRP by photocopying or by other means, in total or part, at the request of other institutions or individuals for the purpose of scholarly research.

I understand that my MRP may be made electronically available to the public.

Vasti Montiel 


\title{
DRESSING DOWN MIGRANT SEX WORK: THE GLOBAL ANTI-TRAFFICKING REGIME, LEGAL EMPLOYMENT RIGHTS, AND CANADA'S TEMPORARY FOREIGN WORKER PROGRAM
}

\author{
Vasti Montiel \\ Master of Arts 2016 \\ Immigration and Settlement Studies \\ Ryerson University
}

\begin{abstract}
This paper analyzes the contemporary global anti-trafficking regime and discusses the destructive influence this regime has had on the lives of migrant sex workers. Through the use of public documents and academic literature, I deconstruct the global anti-trafficking discourses and argue in favour of more viable rights-based solutions (e.g., labour rights, immigration rights, and sexual rights) for combating human trafficking. Within this analysis, I explore the Canadian government's gradual commitment to combat human trafficking through the gradual discontinuation of the exotic dancer visa, and eventual implementation of the migrant sex worker ban. In formalizing its commitment to combating trafficking, the Canadian government has implemented restrictive policy measures terminating migrant women's ability to legally access the Canadian sex industry. While this type of employment was problematic in many ways, the Canadian government should have addressed these issues through rights-based policy initiatives instead of prohibiting access as part of its anti-trafficking campaign.
\end{abstract}

Key Words: migrant sex workers, human trafficking, temporary foreign worker program, exotic dancer visa, anti-trafficking policy. 


\section{ACKNOWLEDGEMENTS}

This Major Research Paper (MRP) became a reality (and not just a figment of my mind) with the generous support of many individuals. I would like to extend my sincere gratitude to all of them.

Foremost, I would like to acknowledge my supervisor, Dr. Sedef Arat-Koç, whose expertise, understanding, generous guidance and support made it possible for me to work on a topic that is of profound interest to me. It was a great pleasure working with her.

I would like to express my gratitude to the second reader of this MRP, Dr. Doreen Fumia, for finding the time to read my long 98-page study and providing me with unanticipated positive feedback. This unexpected feedback served to affirm my doubtful mind that I had written an academically sound research paper and that my hard work paid off. I will always be grateful for her encouraging words.

A special thank you to my best friend, Katerine Stewart, who is always there if I need a distraction, shoulder to cry on, or a soundboard for my plethora of ideas. Thank you always, through thick and thin.

I would like to thank my family whose patience, love, and support throughout my academic career has been greatly reassuring and comforting. Special thank you to my youngest siblings, Kaleb and Ella Montiel, for always making me smile amidst adversity.

Lastly, I would especially like to acknowledge my mother, who not only instilled in me a hunger for academic achievement but also allowed me to sow my own roots and grow. 
For Cody, whose unwavering love and support made this MRP possible. 


\section{TABLE OF CONTENTS}

Author's Declaration $\quad$ ii

Abstract iii

Acknowledgements $\quad$ iv

Dedication $\quad$ V

Table of Contents vi vi

List of Abbreviations viii

$\begin{array}{ll}\text { Introduction } & \text { page } 1\end{array}$

Chapter I. Understanding the International Flow of Migrant page 10 Women and the Concerns Surrounding Human Trafficking

Women as Migrants and The Past and

page 10

Present Human Trafficking Discourses

Global Perceptions: Migrant Women and

page 15

the Sex Industry

Human Trafficking Discourses and

The Feminist Debate: a Brief Review of the Literature

page 19

Chapter II. Global Perspectives: Examining the Anti-Trafficking page 29 Regime and the Consequences that have ensued for Migrant Sex Workers

Turning anti-Prostitution Discourse into

page 29

anti-Trafficking Policy: the Making of the

United Nations Trafficking Protocol

The Definition of Trafficking:

page 34

Inconsistencies With Implications for Migrant Sex Workers

page 41

Migrant Sex Workers as 'Victims of Trafficking'

page 46

The Trafficking Protocol, Crime Control,

and Security Measures: Further Implications for Migrant Sex Workers 
The United States and the

Trafficking Victims Protection Act of 2000

page 52

Chapter III. The Case of Canada: Exploring the Intersections

page 60

Between Migrant Sex Workers, the Anti-Trafficking Regime, and

the Temporary Foreign Worker Program

Exotic Dancing in Canada: a Brief History

page 60

The Temporary Foreign Worker Program

Strippers as Temporary Workers: Origins of The Exotic Dancer Visa

page 62

Trafficking in Women by way of the Exotic Dancer Visa:

page 66

Partial Truths and Complete Consequences

Prohibiting Migrant Sex Work:

page 75

The Unmaking of Canada's Exotic Dancer Visa

Chapter IV. A Comparative Analysis: Evaluating the Exotic Dancer Visa Program against the Low-Skilled Stream of the TFWP

page 86

Sex Industry Standards and Labour Protections for

page 86

Low-Skilled Workers: a Case Against Canada's Migrant Sex Worker Ban

Conclusion

page 97

References

page 99 


\section{LIST OF ABBREVIATIONS}

$\begin{array}{ll}\text { AEAC } & \text { Adult Entertainment Association } \\ \text { APEC } & \text { Asia-Pacific Economic Cooperation } \\ \text { CBSA } & \text { Canadian Border Services Agency } \\ \text { CIC } & \text { Citizenship and Immigration Canada } \\ \text { CATW } & \text { The Coalition Against Trafficking in Women } \\ \text { ESDC } & \text { Employment and Social Development Canada } \\ \text { GAATW } & \text { Global Alliance Against Traffic in Women } \\ \text { GTA } & \text { Greater Toronto Area } \\ \text { HRDC } & \text { Human Resources Development Canada } \\ \text { HRSDC } & \text { Human Resources and Skills Development Canada } \\ \text { IRPA } & \text { Immigration and Refuge Protection Act } \\ \text { IMF } & \text { International Monetary Fund } \\ \text { LMIA } & \text { Labour Market Impact Assessment } \\ \text { LMO } & \text { Labour Market Assessment } \\ \text { METRAC } & \text { Metropolitan Action Committee on Violence Against Women and Children } \\ \text { NGO } & \text { Non-Governmental Organization } \\ \text { NOC } & \text { National Occupational Classification } \\ \text { NIEAP } & \text { Non-Immigrant Employment Authorization Program } \\ \text { NAFTA } & \text { The North American Free Trade Agreement } \\ \text { RCMP } & \text { Royal Canadian Mounted Police } \\ \text { STAR } & \text { Sex Trade Advocacy and Research } \\ \text { TFWP } & \text { Temporary Foreign Worker Program } \\ \text { TFWs } & \text { Temporary Foreign Workers } \\ \text { TIP } & \text { Trafficking in Persons Report } \\ \text { TVPA } & \text { Trafficking Victims Protection Act of 2000 } \\ \text { TVPRA } & \text { Trafficking Victims Protection Reauthorization Act } \\ \text { WHISPER } & \text { Women Hurt in Systems of Prostitution Engage in Revolt } \\ \text { UN } & \text { United Nations } \\ \text { UNODC } & \text { United Nations Office on Drugs and Crime } \\ & \end{array}$




\section{INTRODUCTION}

In Canada, there is a widespread belief that there is a significant problem of both internal and international forms of human trafficking (Kaye, Winterdyk, and Quarterman, 2014, p. 25). Indeed, according to the United States (U.S.) Department of State, Citizenship and Immigration Canada (CIC), the Royal Canadian Mounted Police (RCMP), and the Canadian Department of Justice, Canada has been identified as a source, transit, and destination country for men, women, and children subjected to sex trafficking, and a destination country for men and women subjected to forced labour (U.S. Department of State, 2014, p. 125, Timoshkina and McDonald, 2011, p. 5, Department of Justice Canada, 2015, p. 10). Beginning in the 1990s, the trafficking and smuggling of persons emerged as a subject of debate in Canada with the focus of concern centering on women trafficked by crime syndicates to work in Canada's commercial sex industry (Bruckert and Parent, 2004, p. 1). In particular, the presence of foreign women in Canadian exotic dance clubs and strip bars has been a specific subject of heated debates since the early 1990s, when the number of migrant dancers from underdeveloped countries in Asia, Latin America, and Eastern Europe increased dramatically. This increase however was not the result of the mass trafficking of women, as was widely suspected, but the shortage of Canadian exotic dancers entering the sex industry. This shortage allowed for the operation of a special immigration process permitting employers to source foreign women through the exotic dancer visa (RCMP, 2010, p. 11-12, STAR, 2004, p. 5-6). By the late 1990s however, as panic over human trafficking peaked both internationally and internally, Canada became heavily involved in the negotiations leading to the adoption of the United Nations Protocol to Prevent, Suppress and

Punish Trafficking in Persons, Especially Women and Children (Trafficking Protocol), supplementing the Convention against Transnational Organized Crime (Organized Crime 
Convention). Canada was also among the first nations to sign (December 2000) and ratify (May 2002) the international instruments thereby formalizing its commitment to fight organized crime and cooperate with other countries in combating human trafficking and smuggling (OxmanMartinez, Hanley and Gomez, p. 2005, p. 9).

As a direct consequence of Canada joining the international fight against human trafficking, the exotic dancer visa has been portrayed as both a conduit to the unlawful side of the sex trade for migrants, as well as a chink in Canada's border armor. Additionally, allowing migrants entry into Canada's sex industry has also been argued to provide a legal crevice permitting other forms of international organized crime to infiltrate (Macklin, 2003, p. 481). Amid the growing international pressure to implement more severe anti-trafficking initiatives, both the United Nations and the United States have voiced criticisms of Canada's apparent lackluster anti-trafficking record. The United States in particular has condemned Canada for being an easy target for trafficking activities due to its supposed lenient immigration practices (De Shalit et al., 2014, p. 394). More importantly, due to the continuation of the exotic dancer visa long after Canada's signature of the Trafficking Protocol, it was even suggested, by both the United States and Canadian government critics, that Canada's immigration policies facilitate the sexual exploitation of migrant women and human trafficking (Roots, 2013, p. 27, Gordon, 2006).

In response to the international outcry for more stringent anti-trafficking policies and in an effort to fulfill the requirements of the international conventions, the Canadian government has recently fortified its position on human trafficking. Yet, as Canada's anti-trafficking policies continue to be widely influenced by dominant international human trafficking discourses, conceptions of trafficking in Canada have come to rely on highly emotive, vague, or contradictory rhetoric rather than concrete evidence. These prevailing discourses frame the issue 
of trafficking as a hidden evil that require social attention, resulting in a strong focus on media campaigns and legal action. They have also produced a stark simplified depiction of trafficking, trafficking victims, and traffickers that allows for selective comprehension, exaggeration, and misinterpretation of events (De Shalit et al., 2014, p. 388-389). This stark simplification is exhibited within the Canadian sex trade, which has not only been excessively understood as singularly fostering the sexual exploitation of foreign women, but also, grossly over exaggerated in terms of the extent of organized crime syndicates operating within Canada's borders (Government of Canada, 2012, Department of Justice Canada, 2015, p. 10, RCMP, 2010). This sex industry perversion along with the global pressure and panic surrounding human trafficking ultimately cumulated in the implementation of Canada's latest human trafficking prevention measures.

On July 14, 2012, the 'Protecting workers from abuse and exploitation' Ministerial Instructions were issued by CIC prohibiting legal access to the sex trade within the Canadian Temporary Foreign Worker Program (TFWP) for migrant sex workers. These instructions state that applications from "foreign nationals seeking to work for an employer that is in a sector where there are reasonable grounds to suspect a risk of sexual exploitation are not to be processed" (Citizenship and Immigration Canada, 2014). These instructions not only succeed in terminating legal access to the exotic dancer visa but the Canadian sex trade altogether. From these latest policy changes it is evident that migrant sex workers are one of the target groups who are bearing the brunt of Canada's redefined anti-trafficking law-and-order agenda (Jeffrey, 2005, p. 33, Lepp, 2002, p. 3). The pressure placed on Canada to conform to the global understanding of trafficking has ultimately had dire consequences in terms of migrant women's ability to work legally within the Canadian sex industry. 
The objective of this dissertation is to provide an analytical study of the contemporary global anti-trafficking regime and the destructive influence this regime has had on migrant sex workers. My aim is to argue that in conforming to the global understanding of human trafficking, the Canadian government has implemented restrictive policy measures that narrow the concerns surrounding trafficking away from issues leading to labour migration and absence of labour regulations in the informal-sector to one singularly focusing on combating forced prostitution and sexual exploitation. In consequence, migrant women's ability to access safe and secure employment in the Canadian sex industry is overshadowed by trafficking discourses based on a global understanding of vulnerability and victimhood.

This paper begins by discussing the historical and global discourses concerning human trafficking and the international flow of migrant women, while identifying the specific concerns associated with prostitution, sex work, and migrant sex workers in particular. The next section particularly focuses on the key anti-trafficking policies implemented by both the United Nations and United States and exported globally for (most often) unavoidable domestic consumption. Then, this study will examine the implementation and use of the exotic dancer visa centering on the employment conditions within the Canadian sex trade, specifically where it concerns the exotic dance industry. Subsequently, this study will analyze the way in which the Canadian government gradually legislated a commitment to combating human trafficking through the gradual devolution of the exotic dancer visa, and the eventual implementation of the Ministerial Instructions. This is then followed by an analysis of the low-skilled stream of the TFWP, in order to provide a comparison between this program and the prohibited migrant sex trade. In making this comparison my aim is to provide the framework for a policy alternative to the current migrant sex worker ban. Within this policy alternative I assert that the Canadian government 
should have addressed the issues of potential exploitation within the Canadian sex industry through rigorous labour laws and policy initiatives, like it did for the low-skilled stream of the TFWP, instead of prohibiting access as part of its anti- trafficking campaign. Overall, my intention is for anti-trafficking policy to be viewed from a different perspective from that prescribed by the international community. Through this, it is my assertion that anti-trafficking policies should position migrant sex workers as rights-bearing individuals who deserve genuine protection against exploitation and therefore, should be more focused on the employment rights of migrant sex workers rather than stripping them of the right to work completely. ${ }^{1}$

For this study, I will employ a "Third World" or "Transnational" feminist framework. According to Third World feminist author Kamala Kempadoo, this perspective takes up trafficking as both a discourse and a practice that emerges from the intersections of state, capitalist, patriarchal, and racialized relations of power with the operation of women's agency and desire to shape their own lives and strategies for survival and livelihood. Furthermore, by taking agency and sexualized labour into account, engagement in sex industries and sex work abroad appear as possibilities that women willingly or consciously undertake within specific cultural, national, or international parameters (Kempadoo, 2005, p. 36-37). This perspective maintains that there should be a distinction between trafficking and migration and that sex work should be treated as a type of labour and discussed within the context of capitalist globalization, exploitative labour practices, and imperialist interventionism (Alvarez and Alessi, 2012, p. 148).

\footnotetext{
${ }_{1}^{1}$ Pursuant to the Ministerial Instructions, applications submitted from both within and outside Canada to work in any aspect of this industry (e.g., strip clubs, massage parlours, escort services) are automatically refused. As migrant women predominantly worked in this industry through the exotic dancer visa, the Ministerial Instructions removed their ability to access legal employment not only within Canada's sex industry but Canada altogether. In consequence, foreign women must now find another legal category (e.g., Live-in Caregiver) to be able to come to Canada as migrant workers. However, most often these other legal employment categories have a higher threshold in terms of education and employment experience making it near impossible for a large majority of foreign women to access. As a result, the Ministerial Instructions succeeded in eliminating a feasible category for migrant women to access legal employment in Canada. Making their ability to cross-borders globally as independent migrants that much harder. This will also be discussed in further detail in Chapters II and III.
} 
However, within this framework Kempadoo argues that we are also cautioned against the "treachery of authenticity" and of falling into the trap of constructing an essentialist unitary notion of the Other - the Third World women, the migrant, or sex worker who is valorized and represented as pure and unentangled, and who, in such a representation, is ultimately silenced. For this reason it is important to acknowledge that migrant women and sex workers may be both victim and agent simultaneously, or at different stages in the process of migration. Recognition of the complex and sometimes contradictory subjectivities, positionalities, and claims of migrant sex workers is critical to this framework and for finding a workable solution to anti-trafficking policy reform (Kempadoo, 2012, p. xxii).

This theoretical framework is of particular relevance to my study of Canada's restrictive anti-trafficking policy measures because it offers a different understanding of human trafficking compared to the dominant international anti-trafficking discourses. For instance, the dominant trafficking paradigm makes no distinction between trafficking and migration. In this regard, Third World feminists contend that equating trafficking with migration has led to simplistic and unrealistic solutions such as, in order to prevent trafficking there is a move to stop those who are deemed vulnerable from migrating (Sanghera, 2012, p. 11). This is the exact logic that Canada's migrant sex worker ban follows. If there is no longer a legal category for migrant sex workers to obtain employment, then fewer vulnerable women will be migrating to Canada in order to work in the possibly exploitative sex industry. Yet, according to the Third World theoretical perspective, conflating trafficking with migration in an unproblematic manner results in reinforcing the gender bias that women need constant male or state protection, and therefore must not be allowed to exercise their right to movement (Sanghera, 2012, p. 11). As a result, in terminating access to the sex industry as opposed to making categorical labour and migration 
related changes, the Canadian government is reinforcing this gender bias while restricting women's right to legal international movement. Since the purpose of this study is to argue against the migrant sex work ban as a means to combat trafficking and in favour of legal employment and regulated labour standards for migrant sex workers, it is imperative to have a framework offering a diverging perspective on the mainstream issues of trafficking, migration, and labour.

Additionally, for this study I recognize that migrant women have agency in making their own choices and therefore can consent to working in the sex industry (Tomkinson, 2012, p. 58). However, my aim is not to romanticize employment in the sex industry in any way for the reason that sex work is a limited occupational choice among other gendered and discriminated forms of work available to women (Kissil and Davey, 2010, p. 6). Accordingly, many women and girls 'elect' to join the sex trade rather than join the 35 percent of the global female workforce who earn poverty-level wages. Therefore, although sex work is a 'choice,' any such "freedom" is contingent upon the existence of a particular (and highly unequal) set of political, economic, and social relations, since in general, people "choose" neither wage labour nor sex work unless denied access to alternative means of subsistence (Davidson O'Connell, 2002, p, 94-95).

Discourses about human trafficking, abuse, and agency are deeply gendered in the sense that they are predominantly perceived as mostly affecting women. While I am limiting my discussion to women migrant sex workers, it is equally important to note that many migrants who sell sex are also transsexual and/or transgender individuals, and men (Agustín, 2005, p. 97). Even though discussing transsexual, transgender, and male migrant sex workers is beyond the scope of this paper, I acknowledge their existence within the global sex industry because I do not 
wish to disqualify their experiences as migrant sex workers within the international antitrafficking paradigm.

In the last 30 years the phrase 'sex work' has been coined, broadly referring to sexual commerce of all kinds in an attempt to reduce the stigma attached to the label prostitute and to convey more professionalism. Moreover, the definition of sex work is even more complex as compared to prostitution, since it includes all the sub-categories of informal and formal sex work (e.g., illegal prostitution versus legal stripping) (Kissil and Davey, 2010, p. 3). Audrey Macklin (1999) refers to sex workers as women who "strip, lap/table dance, or exchange sex for money" (p. 25). However, the definition of 'exchange of sex for money' limits the possibilities of a wider exchange of multiple forms of restitution that may not necessarily be monetary in value and does not take into account that these restitutions can be bestowed within the more complex subcategories of informal and formal sex work (Kissil and Davey, 2010, p. 3). For instance, in interviews conducted with sex trade workers in Moscow, Laura Agustín quotes a sex worker stating,

you have to pay for your right to live in the capital, to have a good job and a flat with what you have got. With your body... today thousands of girls are calmly and calculatedly selling themselves. The stupider ones do it just for the money, those with more brains and bigger plans do it for a prestigious job and a place to live (2007, p. 33).

Due to the various ways in which sex workers can be compensated for their work, for the purpose of this study, 'sex work' refers to, stripping/exotic dancing, working for an escort service, massage parlour, virtual sex internet service or underground brothel, lap/table dancing, and the exchange of sex and/or sexual services for some form of restitution.

The interchangeable terms sex industry and sex trade attempt to convey the large scale of sex markets in general, their capacity to generate income, their interrelationships with other large 
industries and infrastructures, and also the diversity of the business involved (Agustín, 2007, p. 65). The industry can also be viewed as an array of sites including: brothels, bars, clubs, discotheques, cabarets, sex shops, peep shows, massage parlours, fetish clubs, and in fact, anywhere that occurs to anyone (inclusive of boats, airplanes, automobiles, and the street). In many activities, consumers and vendors are located in different places, interacting via online cameras, chat or videos, or via telephones. In the case of magazines and films, time as well as space separates the moment of sexual production and sexual consumption (Agustín, 2007, p. 66). Taking all these specifics about the sex industry and sex work into account, the term 'migrant sex worker' is used in this study as an umbrella term to describe foreign women classified as trafficked, smuggled, non-status, illegal, undocumented or irregular migrants, and legal newcomers working in formal or informal establishments of Canada's sex trade (Timoshkina, McDonald, and Wellesley Institute, 2009, p. 3). I now turn to the introductory discussion on the historical and global discourses concerning human trafficking and the international flow of migrant women. 


\section{CHAPTER 1}

\section{UNDERSTANDING THE INTERNATIONAL FLOW OF MIGRANT WOMEN AND THE CONCERNS SURROUNDING HUMAN TRAFFICKING}

\section{Women as Migrants and The Past and Present Human Trafficking Discourses}

In the late nineteenth century, accounts of "white slavery" fueled migration discourses with stories of young white women forced into prostitution and the familiar tale of loss of female virtue (Ahmed and Seshu, 2012, p. 152, Doezema, 2010, p. 1, p. 3). At that time, "white slavery" came to mean the procurement, by force, deceit, or drugs of a white women or girl against her will, for prostitution (Doezema, 2000, p. 25). According to feminist scholar Jo Doezema (2000), the trigger for what she terms the "white slavery panic," resulted from the huge increase in migration between 1860 and the outbreak of the First World War, of which women formed a large part (p. 39). A formidable portion of this increase stemmed from the globalization of capitalism and the consequent internationalization of wage labour beginning in the twentieth century, which led to the mass migration of both male and female labourers, mostly from lower class backgrounds, across international borders (Roots, 2013, p. 23). In this respect, according to Doezema, the campaign against "white slavery" coincided with the mass migration of thousands of women from Europe and Russia to the America's, South Africa, other parts of Europe, and Asia (Doezema, 2000, p. 39). Campaigns against "white slavery" were said to protect 'vulnerable' women from sexual exploitation and a life of prostitution and immorality (De Shalit et al., 2014, p. 397). Historically (and recently as well), men who migrated tended to be viewed as active, adventurous, brave, and deserving of admiration. While for the same behaviour, women were pictured as foolish or naïve potential victims and thus deserving of either rescue or punishment (Doezema, 2000, p. 41). Therefore, accounts of "white slavery" served as 
"cautionary tales" for women and girls that men could travel abroad but unescourted white women faced sexual danger and/or corruption (Doezema, 2000, p. 41). However, in reality the myths around "white slavery" were grounded in the perceived need to regulate female sexuality under the guise of 'protecting' women. They were further indicative of deeper fears and uncertainties concerning national identity, women's increasing desire for autonomy, foreigners, immigrants, and colonial peoples (Doezema, 2000, p. 24).

Academics have noted that present day concerns with prostitution and trafficking in women find a historical precedent in the campaigns against "white slavery" (Doezema, 2010, p. 3-4, Doezema, 2000, Ahmed and Seshu, 2012, Roots, 2013). To begin, women's migration has not slowed down but accelerated due to the ongoing destructive effects of globalization (Lepp, 2002, p. 5). As trade liberalization has forced open the economies of previously colonized countries to greater exploitation by multinational corporations, the conditions that push women into migration have been exacerbated (Thobani, 2001, p. 30). Furthermore, internationalized labour markets, and accompanying new opportunities, have opened up potential destination countries for a growing supply of both skilled and unskilled migrants from less developed countries. At the same time, for labour-sending countries, urbanization, internal rural to urban migration, growing working-age populations, raising education attainment, widening income disparities between global North and South countries, and environmental changes have become key aspects influencing a person's decision to migrate (Miller and Baumeister, 2013, p. 16, Lepp, 2002, p. 5). In terms of women migrants, the Global Alliance Against Traffic in Women (GAATW, 2010a), has noted that the term feminization of labour migration or the feminization of migration has been used to describe the increasing number of working-class women migrating autonomously for most often precarious (i.e., temporary, insecure, strenuous) work (p. 13). In 
addition to the factors mentioned above, policies of 'structural adjustment' imposed by the International Monetary Fund (IMF) since the late 1970s on third-world countries seeking loans or wanting to refinance debt, have also played an important part in emigration from these countries. Structural adjustment policies mandate severe cuts in government spending, and subsequently social programs predominantly lose funding first before other programs. Consequently, women, who predominate in the social sector, lose their income source as well as sources subsidizing basic needs. As a result, structural adjustment policies are often blamed for the disintegration of families and the migration of women looking for work far from home (Agustín, 2007, p. 24).

Feminization of migration is the product of a quickly globalizing world where there is unprecedented demand for the cheap labour of "Third World" women, making them assume a central role as wage earners for their families (Lepp, 2002, p. 5). Indeed, the GAATW has noted that parent's gender preference for children has now shifted. According to the GAATW's report, parents expressed that they now prefer having girl children as they feel girls are more likely to support the family by working abroad (2010a, p. 13). Women's international migration is also the result of various other factors concerning gender discrimination in source countries including the lack of livelihood opportunities for women, barriers in education (e.g., preference for educating male children over female), unequal economic policies, conflict displacement (e.g., loss of land tenure, violation of land rights, etc.), or other economic, social, or political changes in local contexts (e.g., local production of food is no longer permitted or feasible). Women's migration can be further exacerbated by gender specific factors, such as violence against women in war or conflict zones where rape is used as a tool of war; where domestic violence is socially and legally condoned; or violence occurring if they do not conform to social norms about women 
(including violence against lesbian, bisexual, or transgendered women) (GAATW, 2010a, p. 1112). Although none of these causes is exclusive, and no single condition guarantees migration, a UN report found that women who accept the challenge of migration are increasingly motivated by a desire for personal betterment as well as, or even instead of, family responsibilities (Agustín, 2007, p. 17, p. 19). Nevertheless, international migration in general is often described by a set of interrelated 'push-pull' factors driving the desire to move (Government of Canada, 2012, p. 6, Agustín, 2007, p. 17). For example, armed conflict and/or loss of economic viability in a country of origin may 'push' people away from home, while labour shortages and favourable immigration policies in destination countries may 'pull' them elsewhere (Agustín, 2007, p. 17).

In regards to women's international movements, the sexual division of labour and the reproduction of labour power, in relation to sex work, domestic labour, and the commercial marriage market, emerged as a consequence of structural adjustment policies and globalization (Federici, 2006, p. 122-123). Part of the responsibility for the reproduction of labour power in Europe and North America have been unloaded on to the shoulders of women from the global South and Eastern Europe, with a consequent cheapening of the cost of labour. In other words, governments and employers in the global North have profited from the fact that immigrant women now take care of children or the elderly, clean the homes of other women, who are thus 'liberated' to do salaried work (Federici, 2006, p. 122-123). Consequently, importing female immigrant labour has enabled governments in the developed countries to resolve the housework crisis opened by the women's movement of the 1960s and 1970s that challenged women's confinement to unpaid domestic labour in the global North (Federici, 2006, p. 122, p. 117). In terms of the sexual division of labour, since being a traditional female is a job frequently less desired by women in the global North, women with fewer options in their lives are imported to 
do the 'women's work.' Thus, the location of migrant women in female-specific roles is not a by-product of their immigration; it is the very reason for it (Macklin, 1999, p. 24). By and large, this has not led to a decline in the demand for commercial sex, a systematic redistribution of unpaid domestic labour between the sexes, or an increased market valorization of 'women's work.' Instead, migrant women from poorer countries and with fewer options are recruited to make-up the deficit at a lower cost. In this case, sex-trade workers supply cheaper sex, domestic workers perform low-cost childcare and housework, and so called 'mail-order brides' furnish all three (Macklin, 2003, p. 464). For this reason, sex work, domestic work, and the commercial marriage market are rarely regulated by legislation allowing for conditions that permit and maintain the exploitation of migrant women (McDonald, Moore and Timoshkina, 2002, p. 4).

Akin to the discourse of "white slavery," the most recent wave of moral panic around women's migration began in the 1990s as a result of the increased rate of social, political, cultural, and economic changes taking place on a global scale (Doezema, 2000, Roots, 2013, p. 24). This moral panic also coincided with the increasing demand for women's sexual, reproductive, and domestic services in the informal and invisible sectors of the economy in countries of the global North, like Canada (Lepp, 2002, p. 5). Currently, for women to be able to migrate, two options are available: to arrive with legal documentation, or to arrive illegally. However, as many women cannot gain access to the formal economy of their destination country because they do not have the necessary skills or qualifications to qualify for hard-to-obtain work permits, undocumented, "illegal" migration to work in the informal sector of a country is often the only option (O'Brien, Carpenter and Hayes, 2013, p. 412). For this reason, perhaps not surprisingly, women are disproportionally represented in informal sectors of the economy worldwide. As mentioned above, women migrants constitute a substantial pool of workers, 
offering their reproductive labour in the form of work in the sex trade, domestic work, and/or marital bliss (O'Brien, Carpenter and Hayes, 2013, p. 412, Kapur, 2003). Although all these sectors are collectively known as 'women's work,' as the next section reveals, international migration which results in selling sexual services is positioned by anti-trafficking discourses, as completely different from all others (Macklin, 1999, p. 24, Agustín, p. 2006, p. 36).

\section{Global Perceptions: Migrant Women and the Sex Industry}

Jobs in the sex industry form part of a vast unregulated, unprotected, and informal economic sector. Although migrants engage in many other forms of labour that are also unrecognized and uncontrolled, these provoke neither the passionate desire to help nor the scandalized media gaze as the sex industry does. Furthermore, the association of migrant women with sex work overwhelmingly affects how they are treated, excluding them from migration studies, disqualifying them as travellers and workers, and constructing them as passive objects forced to work and travel in ways they never wanted (Agustín, 2007, p. 11). Studies conducted in various parts of the world consistently show that migrant sex workers remain largely outside the legal, medical and social services structures of host nations. Poor language skills, (typically) undocumented status, limited understanding of foreign laws and regulations, absence of support networks, and subjection to xenophobia results in the extreme marginalization of migrants, putting them at greater risk of abuse and exploitation. Migrants are also more likely to be affected by the negative social dynamics of the sex trade, marked by discrimination on the intersecting basis's of race, nationality, class, age and specific place in the industry's hierarchy (Timoshkina, McDonald, and Wellesley Institute, 2009, p. 8). 
Laws prohibiting or regulating prostitution and migration combine to create highly complex and often oppressive situations for women if they become involved in sex work once abroad. In this instance, the illegal and clandestine status of most foreign sex workers prevents them from accessing health care services and makes them more vulnerable to sexual abuse from clients who refuse to use condoms, exposing migrant women to various sexually transmitted health risks. For this reason, trafficking discourse tends to rely on the assumption that poor women are better off staying at home rather than leaving and possibly getting into trouble (O’Brien, Carpenter, \& Hayes, 2013, p. 412, Timoshkina, McDonald, and Wellesley Institute, 2009, p. 8-9, Agustín, 2007, p. 39). Like the 'white slave trade' discourses of the past, human trafficking discourses in the present are used to 'protect' migrant women from being unwillingly 'trafficked' into the informal sectors of the economy, specifically the sex industry. Human trafficking discourses rely on the assumption that no women would willingly choose employment in this sector of the economy, therefore, they could only have been convinced to leave home through deceit, coercion, and/or force (Agustín, 2005, p. 102).

In the context of Canada, the migrant sex trade is considered almost exclusively an urban phenomenon, concentrated in Toronto, Montreal, and Vancouver. While there are no official statistics on the number of migrant sex workers in the Greater Toronto Area (GTA), before the migrant sex worker ban, anecdotal evidence coming from various sources, including law enforcement and sex worker organizations, suggested that there were several thousand migrants working in Toronto's strip clubs, massage parlours, escort services, underground brothels, and street prostitution (Timoshkina, McDonald, and Wellesley Institute, 2009, p. 8). As will be further discussed, in implementing the migrant sex worker ban the Canadian government has chosen to adopt the view that all migrant sex workers are coerced victims of trafficking and as 
such, need to be 'protected' from the sex industry. Consequently, attempts to address migration in the sex industry, as it is currently understood, have only worsened conditions for women in sex work by further criminalizing and stigmatizing the trade, as well as, making migration to Canada for sex workers, and indeed many women, more difficult (Jeffrey, 2005, p. 35, p. 37).

Regardless of why women migrate, their assertion of the right to mobility, selfdetermination, and development, must not be confused with the violence, force, coercion, abuse, nor fraud that may take place in the course of migration (Kapur, 2003). As has been thoroughly documented, most "trafficked persons" express some personal desire to migrate, and about half of the women in the global sex trade appear to be conscious of the fact that they will be involved in some form of sex work prior to migration (Kempadoo, 2005, p. 38, O'Brien, Carpenter, \& Hayes, 2013, p. 412, Agustín, 2005, p. 101-102). During the course of their journey, it is true that many, but certainly not all, migrants experience coercion and even abuse. They may also experience some form of deception if jobs, wages, or work they expected do not materialize or the working conditions are worse than migrants were anticipating (e.g., working longer hours, no choice in their clients, etc.). But does this mean that their consent to perform the work is completely absent and that they are all 'victims of trafficking' as global anti-trafficking discourses position them to be? It does not. Instead, most migrant sex workers, especially those cast as 'illegals,' are victims of the daily and banal operations of the global capitalist labour markets that are governed by nation-states. These global labour market practices are what make migration into the sex industry a necessity for women with limited options (O'Brien, Carpenter and Hayes, 2013, p. 409, Sharma, 2015).

In the absence of a global debate on the specificity of sex work, the details of labour regulations, and the minimum standards that should be applied to the sex industry, it is 
dangerous to talk about coercion, force, and the inability to consent. Lacking some form of agreement on the standards and norms that should apply to the sex industry, it is impossible for states to separate coerced sex work from extremely poor, but still agreed to, working conditions (O'Connell Davidson, 2006, p. 19). Indeed, even when migrants say they were lied to or feel disillusioned about some aspects of their situation, they typically complain about the working conditions they are forced to accept, and not about the fact that the work is sexual per se. Often they want to remain in the sex industry, but in less exploitative conditions (Agustín, 2005, p. 105). Thus, instead of implicitly accepting the inherent harm of sex work, states should endeavour to ensure that labour regulations are legislated and implemented for the establishment of better working conditions for sex workers and the application of a threshold between acceptable work and actual coerced labour. This way, women are free to assert their right to mobility without the state making blanket assumptions that all sex workers are coerced 'victims of trafficking,' because there would be a legislated distinction between migrant women who work in the sex industry consensually under acceptable working conditions and those who do not.

Discussions surrounding whether women choose to work in the sex industry as a limited option or as coerced victims of trafficking, are not inherently restricted to anti-trafficking discourses. Indeed, two diverging feminist perspectives have long been locked around a polarized argument that constructs sex work as either exploitative or liberating (Kissil, and Davey, 2010, p. 6). As the next section reveals, the substance and weight of this debate have also had vast repercussions for past and present anti-trafficking policies and the affects these policies have had on the women in the global sex trade. 


\section{Human Trafficking Discourses and The Feminist Debate: a Brief Review of the Literature}

Discussions over trafficking, prostitution, and sex work and how they are connected are prominent in contemporary feminist debates concerning human trafficking (GAATW, 2010a, p. 24). Feminist organizations have also played a significant part in anti-trafficking campaigns from the beginning of the twentieth century to present day (Roots, 2013, p. 24). Currently, there are two differing feminist perspectives governing human trafficking debates: anti-prostitution and pro-sex workers' rights feminists. Although, for the sake of clarity regarding this debate these perspectives have been split into two separate groups, it is important to keep in mind that there can be and are diverging perspectives within these two sides that cannot be wholly captured within a pro/anti simplification of the debate.

According to Kempadoo, Roots, Federici, Kissil and Davey, Beran, Tomkinson, and Alvarez and Alessi, the first approach is represented by the perspectives of radical, abolitionist, anti-prostitution/anti-trafficking feminists and advocates (Kempadoo, 2005, p. 36, Roots, 2013, p. 24, Federici, 2006, p. 115, Kissil and Davey, 2010, p. 7, Beran, 2012, p. 22, Tomkinson, 2012, p, 56, Alvarez and Alessi, 2012, p. 148). The focus on female victims of trafficking has historically been associated with anti-prostitution campaigns in England. Josephine Butler, a prominent late $19^{\text {th }}$ century British feminist, linked human trafficking to sexual exploitation through her campaigns against the 'white slave trade' (Alvarez and Alessi, 2012, p. 144). More

recently, since the early 1980s, networks of radical feminists have formed in several countries in response to the global expansion of the sex industry and reports of new trafficking in women (Federici, 2006, p. 113). Within this perspective, prostitution is perceived as neither an expression of sexual freedom nor a form of labour but instead, incorporates practices of genderbased violence, including the sexual abuse of girls, rape, and intimate partner violence 
(Leidholdt, 2004, p. 172). Therefore, prostitution is understood as violence perpetuated against women. This violence however, is not only in the practice of prostitution but more fundamentally in the very idea of "buying sex" which, for radical feminists, is inextricably linked to a system of heterosexuality and male power that represents "the absolute embodiment of patriarchal male privileged" (Kissil and Davey, 2010, p. 7).

Anti-prostitution feminists and advocates argue that prostitution reflects larger systems of gender inequality and oppression, and as a result, involvement of women in prostitution is always nonconsensual (Beran, 2012, p. 22, Kissil and Davey, 2010, p. 7). Radical feminists disagree that prostitution can ever involve free choice by any woman (Kissil and Davey, 2010,p. 7). For this reason, radical feminists are not persuaded by prostitutes who espouse notions of free choice and autonomy but instead, dismiss such proclamations as a reflection of internalized sexism and male privilege. Similarly, radical feminists refuse to believe that prostitution can ever be a harmless private transaction but rather suggest that it necessarily and always involves a powerful means of creating, reinforcing, and perpetuating the objectification of women through sexuality (Beran, 2012, p. 37). The Coalition Against Trafficking in Women (CATW), a US based organization founded in 1992, and other anti-prostitution organizations, such as Women Hurt in Systems of Prostitution Engage in Revolt (WHISPER), have condemned the efforts made by sex workers' organizations to have prostitution recognized as a legitimate occupation. They also condemn the use of the term 'sex worker,' which they claim sanitizes a form of slavery and ignores the high cost paid by women involved in prostitution. At the same time, in the abolitionist feminist's view, since prostitution amounts to submission to male needs and the pragmatic relations of sexual subordination, the only acceptable solution is to abolish it (Federici, 2006, p. 129). Interestingly enough, despite their differing positions on other gender- 
based issues, radical feminists seem to share some basic assumptions about prostitution with social conservatives. For instance, when implementing the 2000 Trafficking Victims Protection Act (TVPA) in the United States, the Bush administration established a legal definition of 'severe forms' of trafficking that clearly distinguished between 'sex trafficking' and trafficking of a person 'for labour or services.' By separating sex trafficking from other forms of labour trafficking, the TVPA reinforces the traditional-and distinctly radical feminist-notion that actions involving "sex" and "intimacy" cannot be considered "real work" (Lerum et al., 2012, p. 87, Simmons and David, 2012, p. 70).

How does the anti-prostitution position see the connections between migration, sex work and trafficking? And how does it influence contemporary discourses on human trafficking? To start with, within the anti-prostitution/radical feminist perspective, it is assumed that migrant women never freely enter into sexual relations or never freely choose employment in the sex trade. Rather, migrant women are seen as always forced into prostitution or trafficked - through the power and control exercised over their lives and bodies (Kempadoo, 2005, p. 36). In a similar perspective, feminist abolitionists believe that there is no distinction between women who choose to do sex work and those who were trafficked into sex work because prostitution intrinsically involves the victimization of women, regardless of their level of agency as migrant workers (Alvarez and Alessi, 2012, p. 148). Additionally, feminist abolitionists have insisted that violence is an inevitable and pervasive feature of the 'sexual slavery' that is prostitution and have called on governments and international bodies to act against 'sex trafficking' on the grounds that migrant women in the sex industry are routinely subjected to rape, beatings, imprisonment, and torture. In the same vein, this perspective believes that the victim of sexual slavery can only alter her status as a victim by being rescued or freed from her condition as a 
prostitute (O’Connell Davidson, 2006, p. 16-17). As I will later discuss, this saving and rescuing narrative has conceived a multitude of problems for migrant sex workers. Moreover, this approach exclusively focuses on women in the sex industry as the only victims of human trafficking but ignores the larger problem of the violation of migrant's rights within other informal sectors of the economy (Tomkinson, 2012, p. 57). Unfortunately, this is the perspective that currently informs international, regional, and domestic human trafficking discourse and legislation as well as global anti-trafficking campaigns (Tomkinson, 2012, p. 51). As discussed in detail in the following paragraphs, critique and objections to the implications of this approach are articulated from the second prominent feminist perspective in the contemporary human trafficking debate.

According to Kempadoo, Beran, Federici, Alvarez and Alessi, Jeffrey, and Tomkinson the second approach to the human trafficking debate is represented by the perspectives of "Third World" or "transnational" feminists, liberal and socialist feminists, and pro-sex workers' rights feminists and advocates (Kempadoo, 2005, p. 36, Beran, 2012, p. 34, Federici, 2006, p. 115, Alvarez and Alessi, 2012, p. 145, Jeffrey, 2005, p. 34, Tomkinson, 2012, p. 57). Beginning in the 1970s, a movement emerged in Europe and the U.S. to win for prostitutes the same rights as those extended to other workers. The rise of the prostitutes' rights movement must be understood in the context of the profound legitimation crisis that invaded every aspect of social and cultural life in Europe and the U.S. in the 1960's and 1970's, finding its most direct expression in the resurgence of social radicalism. The feminist revolt against the gender hierarchies underpinning the sexual division of labour challenged women's confinement to unpaid domestic work and analyzed housework as an economic activity that catered to the reproduction of the workforce. Thus feminists opened the door to redefining female sexuality as work. At the same time, 
prostitution was also redefined, practically and theoretically, as an aspect of reproductive work (Federici, 2006, p. 116-117). Therefore, by the 1980s, the 'sex work' position emerged from some sex workers' rights organizations and a number of international gatherings, such as the World Whores Congress held in Amsterdam in 1985 and 1986, to make the public more aware of the reality of sex workers' rights (Jeffreys, 2009, p. 316, Federici, 2006, p. 117).

The "Third-World" or transnational feminist perspective takes up trafficking as both a discourse and practice that emerges from the intersections of state, capitalist, patriarchal, and racialized relations of power (Kempadoo, 2005, p. 36). Most importantly, unlike the first approach, migrants are not simply positioned as victims. Rather, they are co-located as agentic, self-determining subjects who are capable of negotiating relations of power (Kempadoo, 2005, p. 37). From this perspective, sex work is an occupational choice among other gendered and discriminated forms of work available to women (Kissil and Davey, 2010, p. 6). Pro- sex worker's rights advocates further point out that characterizing prostitution as a uniquely degrading and dangerous occupation is arbitrary since, given the state of the global labour market, the alternatives open to women (domestic work or work in a sweat shop), are no less dangerous or humiliating, nor do they spare women from sexual assault or exploitation (Federici, 2006, p. 130). Thus, instead of conceptualizing prostitution itself as an inherent violence to women, it is the working and living conditions women may find themselves in once inside the sex trade; accompanying this is the violence and terror that accompany travel into and work within, an informal/underground economic sector that is taken to violate women's rights and is seen to constitute trafficking (Kempadoo, 2005, p. 38).

Feminists academics within this perspective are particularly opposed to the conflation of sex work and human trafficking and argue for the need to consider human trafficking within a 
wider framework of the vulnerability of migrants as a result of the inaccessibility or absence of legal immigration options (Tomkinson, 2012, p. 58). Ratna Kapur (2003) argues that conflating trafficking with migration results in reinforcing the gender bias that women and girls need constant male or state protection from harm, and therefore must not be allowed to exercise their right to movement or right to earn a living in the manner they choose. Third World feminists and some liberal and socialist feminists have proposed that there should be a distinction between trafficking and migration and that sex work should be treated as a type of labour and discussed within the context of capitalist globalization, exploitative labour practices, and imperialist interventionism (Alvarez and Alessi, 2012, p. 148). According to the Global Alliance Against Trafficking in Women (GAATW), a women's rights advocacy group, trafficking takes place because legal or "regular" channels for labour migration can be extremely limited for working class women therefore leaving traffickers, smugglers, or unlicensed brokers as their only option to access routes barred by governments (GAATW, 2010a, p. 19, p. 16). While pro-sex worker's rights feminists and advocates do accept the fact that there are migrant women coerced or forced into sex work, a minority of cases in which women are abducted, "chained to beds in brothels" and held as sex or other types of slaves are rarely documented. Rather, transnational feminists argue that it is within labour recruitment and migratory processes and/or work sites at the destination that coercion, extortion, physical violence, rape, deception, and detention take place (Tomkinson, 2012, p. 57, Kempadoo, 2005, p. 37).

Feminist academics within this approach oppose the victimist language taken up by the current anti-trafficking regime and pitted against women's cross-border movements (Kapur, 2003, Aradau, 2003, p. 2, Agustín, 2005, p. 106). This perspective argues that the labeling of sex workers as 'victims' is an affront to the many assertive, independent, adult women who state that 
they would not subject themselves to the more 'respectable' female job ghettos (e.g., domestic work, sweatshops, etc.). The victimist language is also criticize for ignoring the fact that sex workers may regard their jobs as a form of self-empowerment that provides them with a degree of financial well-being and therefore more control over their own lives (Brock, 1998, p. 22). Feminists within this perspective argue that one of the main problems with the victimist language is that it creates a binary discourse of victim/perpetrator that makes it impossible to talk about migrant sex-workers as rights-bearing individuals who deserve to have those rights respected (Jeffrey, 2005, p. 41). As a result, some pro-sex worker's rights advocates have convincingly argued that the concept of 'trafficking' should be eliminated because it creates a significant misrepresentation of migrant sex work and often results in confusion between labour abuses and trafficking. Thus for pro- sex worker's rights feminists, very similar to my arguments, what is required is the development of strategies which focus on addressing human rights violations and abuses perpetrated against all economic migrants and the promotion of their social and labour rights (Lepp, 2002, p. 6-7).

In summary, the two main questions dividing these diverging feminists perspectives are: i) whether prostitutes are coerced victims or women who have chosen to be employed as sex workers, and ii) whether the solution should be the abolition of prostitution or the granting of equal labour rights through decriminalization and/or legalization (Kissil and Davey, 2010, p. 6). Although the feminist debate has influenced contemporary discourses on human trafficking, some academics are of the opinion that this polarization of the feminist movement on questions of prostitution and sex trafficking has hindered rather than helped the actual women who continuously find themselves in situations of illegality, both as migrants and sex workers (Federici, 2006, Beran, 2012, Kissil and Davey, 2010, Alvarez and Alessi, 2012, Agustín, 2007). 
According to Alvarez and Alessi (2012), while the human trafficking debate offers a new battleground for the prostitution debate, the consequent narrow focus on sex trafficking and prostitution diverts attention away from other forms of exploitation suffered by migrants (i.e., labour exploitation) and hinders the discussion on the role globalized markets play in creating and maintaining vulnerabilities to trafficking (p. 148). Laura Agustín (2007) notes that the interests of migrants who have no right to work and are concentrating on accumulating as much money as they can as quickly as possible may conflict with the interests of sex workers' organizations who want to legitimize the industry. Since the most important fact conditioning migrants' lives is having or not having residency and/or work permits, they often feel that proposals about sex worker rights are irrelevant to themselves (p. 73).

Silvia Federici argues that both feminist strategies and rhetoric are insufficient to confront the new realities that have developed in the world of prostitution and are thus bound to fail even in their own terms. For Federici these 'new realities' are a product of the debt crisis, structural adjustment policies, and the resulting globalization of sex work (p. 120). These international economic policies have created mass diasporas of migrants in search of better economic opportunities, particularly women migrating into the sex trade, while receiving nation states are quickly moving to secure their borders inline with the current xenophobic climate and non-inclusive policies. Since feminist abolitionists deny any rationality to the practice of prostitution, Federici argues that this position precludes any understanding of the meaning of prostitution, especially in the present social context, and of the social forces by which it is structured (i.e., migration for economic purposes). As a result, Federici contends that feminist abolitionists have little to offer to the immigrant woman or to any other sex worker, other than to recommend that they quit their work and denounce their trafficker (p. 130). Therefore, the 
abolitionist's position is quite limiting in terms of the new realities that have developed in a vastly globalizing world filled with restrictive immigration and ever expanding economic policies.

In regards to the second feminist approach, Federici acknowledges that it is an incontrovertible fact that many of the abuses perpetrated against sex workers stem from the lack of legal recognition of their work. However, for Federici, sex-worker advocates do not sufficiently recognize that work in dependent conditions is subjected to the kind of restrictive regulation that sex workers' organizations have rejected, and that as a consequence of globalization even the limited entitlements available to the unionized working class are in jeopardy (p. 132). Thus Federici argues that the sex workers' rights approach is also limiting because even in the "so-called" affluent countries, established workers are experiencing a "race to the bottom,' undermining the possibility of secure employment and access to social entitlements such as pension, health and unemployment benefits, and union representation. All these rights are what sex workers' organizations assume they would obtain if prostitution were recognized as actual work. As a result, Federici argues that this recognition-as necessary as it is - would not be sufficient to guarantee sex workers the safety and benefits they desired unless the "present economic trends were reversed" (p. 133).

Both Beran (2012) and Kissil and Davey (2010) are of the opinion that there needs to be a new conceptualization concerning sex work that is not based on mutually exclusive choices, but instead incorporates the complexity of the prostitution phenomenon, and allows for the various voices of prostitutes to be heard and validated (Kissil and Davey, 2010, p. 16). In this respect, Beran, contends that academic authors must draw from both feminist camps in order to best address the needs of individual prostitutes as well as the broader social and economic goals 
necessary for the advancement of gender equality (2012, p. 45). Likewise, Kissil and Davey argue that the either-or stance of the prostitution debate ignores the possibility that these options are not mutually exclusive and the fact that prostitutes are not a homogeneous group (2010, p. 16). In this vein, Beran maintains that in order to be truly open and receptive to the positions of individual prostitutes, feminist scholars must make a conscious effort to be mindful of their own social locations. For Beran, this consciousness is the only way to ensure that scholars do not silence oppressed women by objectifying them as subjects rather than considering them as equals in finding the best method of policy reform (2012, p. 45).

Prostitution seems to engender some of the most difficult issues in feminism. Even after more than 100 years of public discussion and efforts, prostitution still remains socially constructed as a crime with the prostitute as either criminal or a victim (Kissil and Davey, 2012, p. 16, p. 11). This problematic social construction of prostitution, along with the other antiprostitution/radical feminists discourses and their substantial influence on the Trafficking Protocol definition, will be analyzed in the following section. At the same time, beyond simply problematizing the Trafficking Protocol and subsequent mainstream anti-trafficking policies, it will be argued that critics of the trafficking discourse aim to provide possible alternatives to the damaging effects of the current anti-trafficking policies in order to demonstrate that there are better and more viable solutions outside those prescribed by the regulating bodies. 


\section{CHAPTER II}

\section{GLOBAL PERSPECTIVES: EXAMINING THE ANTI-TRAFFICKING REGIME AND THE CONSEQUENCES THAT HAVE ENSUED FOR MIGRANT SEX WORKERS}

\section{Turning anti-Prostitution Discourse into anti-Trafficking Policy: the Making of the United Nations Trafficking Protocol}

The very first statute on human trafficking, the International Agreement for the Suppression of the White Slave Traffic, was signed and ratified by Belgium, Denmark, France, Germany, Italy, the Netherlands, Portugal, Russia, Spain, Sweden and Norway, Switzerland and the United Kingdom ${ }^{2}$ in 1904 in the wake of the moral panic ${ }^{3}$ surrounding the 'white slave trade' (Bruckert and Parent, 2002, p. 21). The title of the treaty betrayed the racist focus of the signatory states' concern over the sale of white women into prostitution. The whiteness signified by 'white slavery' was both literal and metaphorical. As moral virtue was the property of the bourgeois Anglo-European women and girls, only they were considered potential victims to this form of slavery (Macklin, 1999, p. 25, Macklin, 2003, p. 479). For example, the international community extended no sympathy to the Chinese women and girls brought into Canada at the beginning of the twentieth century and provided as prostitutes to Chinese 'bachelor husbands' because Chinese immigrant men were denied the right to bring their families with them and there were eugenic anxieties and fears against mix-race relationships. Indeed, these women were not recognized as symbols of feminine victimhood, but as agents of Chinese depravity. This

\footnotetext{
2 International Agreement for the Suppression of the White Slave Traffic, Paris, 18 July 1904, League of Nations, Treaty Series, vol. I, p. 83, available from,

https://treaties.un.org/pages/ViewDetails.aspx?src=TREATY\&mtdsg_no=VII-8\&chapter=7\&lang=en

3 According to Stanley Cohen (1972) moral panic refers to an exaggerated reaction, from media, the police or wider public, to the activities of particular social groups. These activities may well be relatively trivial but have been reported in a somewhat sensationalized from in the media; and such reporting and publicity has led to an increase in general anxiety and concern about those activities. Thus, a moral panic is an exaggerated response to a type of behaviours that is seen as a social problem. Furthermore, this over-reaction magnifies the original area of concern, leading to the social group (and, as a consequence, the activities and behaviours they engage in) to be viewed by the wider society as "folk devils" - another term coined by Cohen (cited in March and Melville, 2011, p. 2).
} 
perceived moral inferiority justified exploiting Asians as objects serving the nation-building project rather than subjects who belonged to it (Macklin, 2003, p. 479). By 1949, however, the 'white slavery' terminology had shifted to "trafficking in women and children" as conveyed within the 1949 UN Convention for the Suppression of the Traffic in Persons and the Exploitation of the Prostitution of Others (1949 Convention), which remained in effect until 2000 (Macklin, 1999, p. 25, Roots, 2013, p. 23). Although the terminology used in international law changed, what remained intact was the notion of the young, white middle-class AngloEuropean women who represented a pure and innocent victim unwittingly lured into the sex trade. This solidified the recurring belief that only 'good girls' can be victims of trafficking, thus, anyone who voluntarily enters the sex trade is a 'bad girl' and risks forfeiting entitlements to the concern, respect, and protection of the nation (Macklin, 2003, p. 480).

To no surprise, the 1949 Convention was heavily influenced by an anti-prostitution perspective and deemed prostitution and the traffic in persons to be "incompatible with the dignity and worth of the human person and (to) endanger the welfare of the individual, family, and the community" and therefore, made no distinction between forced and voluntary prostitution. The Convention viewed a prostitute as a victim and did not recognize the possibility or the right of an individual to choose this line of work (Bertone, 1999, p. 17, Roots, 2013, p. 25). As the 1949 Convention was excessively focused on the criminalization of prostitution, it was criticized for ignoring other forms of trafficking (e.g., labour trafficking, mail-order brides, domestic workers, etc.) and for failing to consider domestic trafficking or workplace exploitation (Lerum et al., 2012, p. 85, Bruckert and Parent, 2002, p. 22). Thus, the 2000 Protocol to Prevent, Suppress and Punish Trafficking in Persons, Especially Women and Children (Trafficking Protocol), supplementing the United Nations Convention against Transnational Crime 
(Organized Crime Convention), attempted to correct this problem, by creating an understanding of trafficking in persons as a set of human rights violations applicable to any labour sector (Lerum et al., 2012, p. 85). Yet, as some academics argue, the inception of this Trafficking Protocol has also created an understanding of trafficking in persons that is explicitly linked to efforts to combat all types of organized criminal activities that cross national borders (Kempadoo, 2005, p. 39). This has resulted in a push for managed migration in order to thwart growing concerns over security issues, including transnational crime and terrorism (Miller and Baumeister, 2013, p. 17). At the same time, the narrow focus of an anti-trafficking agenda through the lens of combating other forms of organized crime (such as smuggling and drug trade) means that exploitation that occurs even when a person has migrated through legal and "regular" channels is overlooked (GAATW, 2010, p. 10).

The Trafficking Protocol is interpreted by some critics as an instrument used by Western states and intergovernmental agencies to control global flows of labour and women's sexuality (Kempadoo, 2005, p. 51). The Protocol has also been accused of housing inconsistencies with its definition of trafficking in persons and how the definition should be implemented by signatory states (Agustín, 2006, p. 42). Due to the inconsistency with the trafficking in persons definition, many signatory states continue to equate 'trafficking' with prostitution creating difficult situations for migrant sex workers and those found working in the sex industry in their own countries or abroad (Dottridge, 2007, p. 13, p. 15). The conflation of sex work and trafficking has resulted in immigration policy restrictions regarding women's migration and subsequent work in the sex industry under the guise of protecting 'vulnerable' women from traffickers and environments in which the risk of sexual exploitation can be exacerbated (De Shalit et al., 2014, p. 401). In terms of migrant sex workers, global anti-trafficking policies focus on 'saving and 
rescuing' initiatives as a way to combat human trafficking and removing 'vulnerable' women from the sex industry (Tomkinson, 2012, p. 62). The Trafficking Protocol is therefore not only instrumental in controlling migration flows worldwide but also, facilitating the global suppression of sex work under the guise of combating human trafficking.

In terms of the inception of the Trafficking Protocol, in multiple sessions between 1998 and 2000, the UN Commission for the Prevention of Crime and Penal Justice listened to arguments from two groups lobbying in different directions, specifically around ideas of women's ability to consent and the element of coercion in trafficking (Agustín, 2007, p. 40, GAATW, 2010a, p. 6). Many mainstream human rights organizations, including the International Human Rights Law Group and Human Rights Watch, influenced by the "choice" rhetoric of the sex industry, lobbied in support of a definition of trafficking that required proof of force and deceit (Leidholdt, 2004, p. 177). Other groups, including the Global Alliance Against Traffic in Women (GAATW), formed a Human Rights Caucus calling for a definition that would recognize the distinction between sex work and trafficking, and recognize coercion as an element of the trafficking definition. This meant that the trafficking of men could also be recognized as a human rights violation. On the other side of the debate, anti-prostitution advocates called for a definition that would define all prostitution as trafficking and make the issue of consent irrelevant (i.e., making women seem incapable of providing consent in sex work) (GAATW, 2010a, p. 6). In terms of what the anti-prostitution advocates had proposed, the opposing side was concerned about the oppressive outcome of such legislation on the lives of sex workers and argued that the Trafficking Protocol should avoid adopting a patronizing stance in the name of "protecting" women. This is especially due to the fact that such a stance historically has 'protected' women from the ability to exercise their rights to engage in sex work (Roots, 2013, p. 25). In the end 
however, Human Rights Caucus representatives realized that valuable time was being lost on this debate and therefore, proposed a compromise definition, in which the ambiguous term, "sexual exploitation," was incorporated. The term "sexual exploitation" is ambiguous because it was given no definition, thus allowing signatory states to define and address it as they deem appropriate (Lepp, 2002, p. 3, Dottridge, 2007, p. 4). The implications of this ambiguity will be further discussed in a subsequent section.

After two years of negotiations, involving government delegates and NGOs, and signed by 81 countries in December 2000, the Protocol to Prevent, Suppress and Punish Trafficking in Persons, Especially Women and Children, supplementing the United Nations Convention against Transnational Crime, provides the first international definition of "trafficking in persons," differentiating it from human smuggling which is addressed in the separate Protocol Against the Smuggling of Migrants by Land, Sea and Air (Lepp, 2002, p. 3). Despite this distinction, prior to the finalization of the Trafficking Protocol, Radhika Coomaraswamy, UN Special Rapporteur on Violence Against Women, expressed concern in her report on global trafficking in women submitted to the $56^{\text {th }}$ session of the Commission on Human Rights that the "first modern international instrument on trafficking is being elaborated in the context of crime control" under the International Convention against Transnational Crime, "rather than through a focus on human rights." She insisted that this constituted "a failing of the international human rights community to fulfill its commitment to protect the human rights of women." The Trafficking Protocol does indeed focus principally on "crime control," containing strong law enforcement provision in such areas as "criminalization" (Article 5), "border measures" (Article 11), "security and control of documents" (Article 12), and "information exchange and training" (Article 10) (Lepp, 2002, p. 4). This is not surprising, however, as academics and activists have shown, when 
women are constructed exclusively through the lens of violence - as in, only focusing on trafficking as violence against women - this triggers a series of domestic and international reforms focused on criminal law, which are used to justify state restrictions on women's rights for their 'protection.' As a result, exclusively linking violence against women with trafficking can mask, or present a limited view of other important issues related to trafficking, such as the states' own implication in the exploitation of sex workers and migrant women (Kapur, 2002, p. 6, GAATW, 2010a, p. 23, Jeffrey, 2005, pg. 39). As Coomaraswamy has warned, even with the establishment of two separate Protocols on trafficking and smuggling, migration and sex work are frequently addressed through the same discourses and relations of managed migration, security and transnational crime. This association has vast implications for women's cross border movements and subsequent employment in the sex industry. At this point it is useful to provide a thorough discussion of the term "trafficking in persons."

\section{The Definition of Trafficking: Inconsistencies With Implications for Migrant Sex Workers}

Within the Trafficking Protocol, under Article 3(a) "trafficking in persons" is defined as:

"the recruitment, transportation, transfer, harbouring or receipt of persons, by means of the threat or use of force or other forms of coercion, of abduction, of fraud, of deception, of the abuse of power or of a position of vulnerability or of the giving or receiving of payments or benefits to achieve the consent of a person having control over another person, for the purpose of exploitation. Exploitation shall include, at a minimum, the exploitation of the prostitution of others or other forms of sexual exploitation, forced labour or services, slavery or practices similar to slavery, servitude or the removal of organs ${ }^{4}$."

According to the administrator of the Trafficking Protocol, the United Nations Office on Drugs and Crime (UNODC), the definition contained in article 3 is meant to provide consistency and

\footnotetext{
${ }^{4}$ Protocol to Prevent, Suppress and Punish Trafficking in Persons, Especially Women and Children, Supplementing the United Nations Convention Against Transnational Organized Crime, New York, 15 November 2000, United Nations, Treaty Seriesvol.2237, p. 319; Doc. A/55/383, available from, https://www.unodc.org/unodc/treaties/CTOC
} 
consensus around the world on the phenomenon of trafficking in persons (Miller and Baumeister, 2013, p. 18. UNODC, 2008, p. 3). Simplified, the definition of "trafficking in persons" has three constituent elements: i) The Act (what is done), as in recruitment, transportation, transfer, harbouring or receipt of persons, ii) The Means (how it is done), for example, threat or use of force, coercion, abduction, deception, etc., and, iii) The Purpose (why it is done), meaning for the purpose of exploitation, which includes exploiting the prostitution of others, sexual exploitation, forced labour, slavery or similar practices and the removal of organs (UNODC, 2008, p. 2). Mike Dottridge (2007) has noted however, that the complexity of the definition has brought problems when it has been adopted word for word in national legislation and passed to law enforcement officials as an operational definition of a crime they are supposed to detect or prevent. Dottridge contends that in most contexts it does not function well as an operational definition for law enforcement agencies or others, such as immigration officials. This is because; often such agencies resort to various shortcuts when enforcing the law and, in doing so, often misapply or misinterpret the definition. Likewise, as there is no international definition for the term "sexual exploitation," countries can define and address it as they deem appropriate, giving signatory states a great deal of leeway (Dottridge, 2007, p. 4). As a result, many countries, including Canada and the United States, consider consensual work in the sex industry to be equivalent to the sexual exploitation of migrant women within their borders. Thus, signatory states often deny migrant women legal employment opportunities in the sex trade for fear of enabling human trafficking and going against the mainstream anti-trafficking discourse.

The ambiguity of the term "sexual exploitation" is one of the main problems with the trafficking definition because it allows for a discursive slippage between sexual exploitation and the sex industry, making it possible for signatory states to easily conflate women's migration, sex 
work and trafficking (Agustín, 2005, p. 108). While there are horrific instances of forced migration, deceit, and violence within the global sex trade, discussions of trafficking frequently generalize and confuse a number of different issues and situations and portray all migration within the sex industry as forced. In anti-trafficking discourses it is believed that sex trafficking and sex work overlap in fundamental ways, as those supposedly targeted for commercial sexual exploitation are said to share key demographic characteristics such as, poverty, youth, minority status in the country of exploitation and histories of abuse. Indeed, trafficking narratives tend to universally portray young women from poor countries as victims of criminal gangs that trick or force them into the sex trade, move them against their will across international borders, and hold them in sexual slavery in foreign countries. In these discourses it is also understood that local brothels and strip clubs are usually traffickers' destination of choice and key to their financial success (Jeffrey, 2005, p. 35, Leidholdt, 2004, p. 178). ). The UNODC also adds weight to these narratives by iterating that it is "known that those who traffic women for the purpose of sexual exploitation often make use of exotic dancer visas or similar fraudulent claims to bring women into the countries of destination," thus suggesting a necessary connection between the sex industry and trafficking $(2009$, p. 73$)$. For this reason, there is an implicit acceptance in antitrafficking discourses of the inherent harm of the sex industry towards sex workers in general and migrant sex workers in particular (GAATW, 2010a, p. 24, O’ Brien, Carpenter and Hayes, 2013, p. 407). Yet what anti-trafficking discourses fail to mention is that sexual exploitation is a risk in any situation where women experience human rights violations and narrowing the focus to sex trafficking does nothing to end the abuses to which migrant women in the informal sectors of the economy are often subjected. As a result, trafficking, understood as the sexual exploitation of women within the sex industry, does not occur because of the inherent harm of 
sex work, but because of the failure of anti-trafficking discourses to adequately uphold women's rights as independent migrants (GAATW, 2010a, p. 29, Dottridge, 2007, p. 12, Jeffrey, 2005, p. $35)$.

Another problem identified with the Protocol is precisely about the fact that the term 'trafficking' does not describe a single, unitary act leading to one specific outcome, but rather refers to a process (i.e., recruitment, transportation, and control) that can be organized in a variety of ways and involve a range of different actions and outcomes. This problem is exacerbated by the fact that many of the constituent elements identified in the Trafficking Protocol present definitional problems themselves (i.e., the absence of international consensus regarding the definition of 'sexual exploitation' or 'exploitation' in general), and by the fact that the abuses that come under the umbrella of 'trafficking' can vary in severity, generating a continuum of experience rather than a simple either/or dichotomy (O'Connell Davidson, 2006, p. 8-9). Accordingly, the package of violations covered by the Trafficking definition (i.e., violence, confinement, coercion, deception, exploitation) can and do occur within legally regulated as well as irregular systems of migration and employment, and within legal as well as illegal system of migration into private households (O'Connell Davidson, 2006, p. 10). Consequently, states seeking to operationalize the concept of 'trafficking' have to make judgment calls about the point on the spectrum where they believe 'appropriate' exploitation/force ends and 'inappropriate' exploitation/force begins (O'Connell Davidson, 2010, p. 250). However, since the UNODC contends that the Protocol definition is broad enough to give state parties considerable leeway in tailoring and adapting their national legislation, states can differ in where they believe 'appropriate' exploitation/force ends and 'inappropriate' exploitation/force begins. This means that there will never be a concise and consistent 
implementation of the trafficking definition, as states are free to operationalize the trafficking definition in any way they deem best in order to combat human trafficking within their borders (UNODC, 2014, p. 16).

Canada's efforts to implement the Trafficking Protocol also suffer from shortcomings, with disparities not only between the legislative definition of human trafficking outlined in the protocol and domestic legislation, but also between the Criminal Code of Canada and the Immigration and Refuge Protection Act (IRPA) (Roots, 2013, p. 29). In 2002 Canada was among the first countries to ratify the Trafficking Protocol, enacting two key pieces of anti-trafficking legislation not long afterwards (Kaye, Winterdyk and Quarterman, 2014, p. 26, OxmanMartinez, Hanley and Gomez, 2005, p. 9). Section 118, criminalizing the trafficking in of persons was added to the IRPA in 2002, while Sections 279.01 to 279.04 , creating new offences in regards to human trafficking, were added to the Criminal Code in 2005 (De Shalit et al., 2014, p. 386, UNODC, 2008, p. 99, Bruckert and Parent, 2002, p. 24). According to section 279.01 (1) of the Criminal Code, human trafficking is defined as the recruitment, transportation, concealment, harbouring, or exercising control, direction, or influence over an individual's movements for the purpose of exploitation. In contrast, section 118 of the IRPA defines human trafficking as knowingly organizing (through recruitment, transportation, receipt, or harbouring) the entry of an individual into Canada by means of abduction, fraud, deception, or use or threat of force or coercion (Roots, 2013, p. 29). The Criminal Code offence and the offence under the IRPA are significantly different, with one focusing on exploitation and fear, and the other on cross-border movement and deception (Sikka, 2013, p. 20).

The definitions in both the Criminal Code and the IRPA are slightly broader than the one established in the Trafficking Protocol. The primary distinction between the legislative definition 
in the IRPA and the Trafficking Protocol is the ability to apply the IRPA's anti-trafficking provision to the activities of any one individual rather than just criminal organizations. Additionally, while the Protocol requires evidence to demonstrate that border crossing is for the purpose of exploitation, for the IRPA, the only thing required to determine the crime of human trafficking is the transportation of an individual into Canada by the established 'means' (e.g., abduction, fraud, coercion). Thus, in contrast to both the Protocol and Criminal Code, in the IRPA, a perpetrator is not required to have committed these acts for the purpose of exploitation. Therefore, the IRPA's criteria for proving the crime of trafficking is significantly less demanding than that of the Trafficking Protocol and Criminal Code (Roots, 2013, p. 30, Sikka, 2013, p. 8-9). The inconsistent implementation of the Trafficking definition into Canadian domestic law has had vast consequences in terms of deciding which one specifically applies to trafficking cases in Canada. For example, in their 2010 Human Trafficking Threat Assessment report, the RCMP noted that, "it was apparent during the analysis of past cases, and particularly in investigations involving temporary foreign workers, that the focus on the application of the Criminal Code may need to expend equal consideration to both pieces of legislation to ensure that the appropriate one is applied" (RCMP, 2010, p. 42).

Article $3(b)$ of the Trafficking Protocol notes that the "consent of a victim of trafficking in persons to the intended exploitation set forth in subparagraph $(a)$ of this article shall be irrelevant where any means set forth in subparagraph $(a)$ have been used ${ }^{5} . "$ In other words, the UNODC notes that article $3(b)$ states that if a victim's consent to the intended exploitation is obtained through any improper means (i.e., threat, force, deception, coercion etc.) then the consent is negated and cannot be used to absolve a person from criminal responsibility (2008,

${ }^{5}$ Protocol to Prevent, Suppress and Punish Trafficking in Persons, Especially Women and Children, Supplementing the United Nations Convention Against Transnational Organized Crime, New York, 15 November 2000, United Nations, Treaty Series, vol.2237, p. 319;Doc.A/55/383, available from, https://www .unodc.org/unodc/treaties/CTOC/ 
p. 5). As a result, if a signatory state's laws conform to the Trafficking Protocol requirements, a trafficker would not be able to successfully defend a trafficking charge by presenting evidence that a victim previously engaged in prostitution, knew the purpose of travel, or in any other way consented or agreed to work for someone who subsequently used coercion to exploit the victim (U.S. Department of State, 2014, p. 35). Despite the reconstruction of sex workers as potential victims of sexual exploitation, as opposed to criminalized prostitutes, the outcome of the paradigm remains unchanged. This is because, the manner in which the issue of 'consent' was adopted into the trafficking definition strips women of agency over their own bodies and constructs them as being incapable of decision making, thus, women are seen as constantly requiring the intervention of the law (Roots, 2013, p. 25).

Under the Criminal Code, a persons' ability to consent is made irrelevant if the person was exploited. Likewise as indicated under the IRPA, consent is irrelevant as long as it can be proven that the person was organized to come to Canada by means of deception, abduction, fraud, or use or threat of force or coercion (Sikka, 2013, p. 9, RCMP, 2010, p. 43). These legislations however, especially the provisions set out in the Criminal Code that allow law enforcement agents to deem someone "trafficked" even if they do not identify as such, have solidified an emotional anti-trafficking discourse that typically coincides with stricter immigration controls, enhanced criminalization and surveillance of migrant labour and the sex industry (De Shalit et al., 2014, p. 386).

The ability to negate a migrant sex worker's consent basically pushes them into a perpetual state of victimhood and gives police/law enforcement the freedom to label a variety of offences as human trafficking, since all that is required is evidence of exploitation. Yet, this ignores the fact that not all forms of exploitation are determinates of human trafficking and can 
also occur through perfectly legal channels of migration. At the same time, such assumptions are based on the idea that 'victims of trafficking' (i.e. women) are unable to recognize or are reluctant to admit to being exploited due to coercion and threats from their traffickers, psychological manipulation, and/or threats of physical harm to themselves of their families (Roots, 2013, p. 31). Thus, according to anti-trafficking discourse, 'victims of trafficking' require law enforcement or immigration officials to not only intervene and recognize the exploitation for them, but also rescue these 'victims' from the clutches of the sex industry. While the initial impulse behind the traffic in women discourse appears to be one of 'protecting' the rights of exploited women, this discourse has been strongly condemned by sex workers, including migrant sex workers, as paternalistic and imperialistic. Indeed, as the following section reveals, anti-trafficking rhetoric, such as 'victims of trafficking' and 'saving and rescuing' narratives, have in fact exacerbated the conditions for women in the sex trade because they strengthen the hand of officials without empowering the women themselves (Jeffrey, 2005, p. 34). Additionally, given the different degrees of involvement on migrants' part in initiating their migratory journeys and subsequent employment in the sex industry, "trafficked victim" is a poor description of their varied experiences and discounts what many women say about their own life projects (Agustín, 2005, p. 106).

\section{Migrant Sex Workers as 'Victims of Trafficking'}

Beginning with the 'victimist' language taken up by anti-trafficking discourses and exemplified in the Trafficking Protocol, the word 'victim' may be used in a legal sense, (e.g. for victim of a crime). In the case of 'victims of trafficking', however, the word transmits the notion that these 'victims' are sexually innocent and ignorant. In this vein, one problem is that the 
person designated a 'victim' tends to take on an identity as 'victim' that reduces her to a passive object of others' action. For this reason, migrant women are routinely characterized as pushed, obligated, or coerced, even when their migration and employment in the sex industry was planned (Agustín, 2005, p. 107). When applying the victimist view to migrant women, the image that is produced is that of a naïve Third World migrant, who is sexually constrained, traditionbound, incarcerated in the home, illiterate, and poor. In contrast stands the image of the emancipated Western women who is in control of her income, body, and sexuality. This view is then structured along the contours of colonial thought with the assumption being that, migrant women in the Third World are infantile, backward, and incapable of self-determination or autonomy (Kapur, 2002, p. 18-19). Thus in a view surprisingly similar to that of the 'white slave trade,' today's 'victims of trafficking' function as a cultural myth constructing particular conceptions of migration and the sex industry that are based on the 'innocent,' unwilling victims (Doezema, 2000, p. 24). Furthermore, constructing all migrant sex workers as 'victims of human trafficking' implies that they do not have agency over their own lives when in reality, as previously stated, migrants are often aware of the sexual nature of the work they will be engaging in (Doezema, 2000, p. 47, Agustín, 2005, p. 98). Yet far from 'protecting' migrant women, legal frameworks like the Trafficking Protocol, only succeed in further victimizing them. This is accomplished through limiting a state's obligations towards securing rights and protections for those who are subject to exploitative employment relations and poor working conditions in the sex trade, in favour of adopting a victim centered approach focused on saving and rescuing policies (O'Connell Davidson, 2006, p. 20).

The idea of the 'victim' grounding trafficking discourses has resulted in rescue-driven responses that perpetuate patriarchal and colonial practices that suppress the agency of those 
most affected by such efforts, namely people with precarious migration status, racialized women, and sex workers (De Shalit et al., 2014, p. 389-390). However, saving and rescuing narratives do not contribute to migrant worker's rights since they are constructed in relation to the understanding of women as 'victims' and strip women of their self-determination. As a result, the focus on the 'victim' reinforces the depiction of women in the global South as perpetually marginalized and underprivileged, and has serious implications for the strategies adopted to remedy the harms that women experience (Kapur, 2002, p. 6, Tomkinson, 2012, p. 62). Such strategies include 'rescue' operations in red light districts where the 'victims' who are picked up by police have not been trafficked. Instead they turn out to be migrant sex workers who just want to get back to earning money, rather than being 'protected' from their employers, let alone repatriated back to their country of origin (Dottridge, 2007, p. 15). Indeed, most often migrant women who are 'rescued' are detained and deported for infringing upon national immigration laws and are therefore, generally forced to return to the same conditions that initially prompted their move. As a result, some "victims' end up being "re-trafficked" or are repatriated to situations that propel them to seek new avenues for migration (Kempadoo, 2005, p. 41). For this reason, a broader human rights strategy around sex work, such as one that also includes labour rights, immigrant rights, and sexual rights ${ }^{6}$ is needed in order to chip away at the hegemonic understanding of sex workers as 'victims' who must be rescued and repatriated (Lerum et al., 2012, p. 100).

\footnotetext{
${ }^{6}$ As Judy Fudge and others have shown, there are problems and limitations associated with a legalistic rights perspective. As this study focuses on the problems of the criminalization of certain types of work and workers, it presents the advantages of a rights approach without going into this debate about its limitations and problems. See Fudge, J. (1991). "Reconceiving Employment Standards legislation: Labour Law's Little Sister and the Feminization of Labour." as an example of the problems associated with employing labour-rights based solutions in industries predominated by a female workforce.
} 
The discourse of rescuing 'victims' embedded in anti-trafficking policies results in a failure to address the exploitation of migrant sex workers. First, because it renders invisible the negative implications of anti-sex work and anti-migration laws that make migrant sex workers vulnerable to exploitation in the first place. Second, because it makes it possible to deny protections to women, who may have undeniably been exploited through the migration process or sex work, if they fail to live up to high standards of victimhood (Jeffrey, 2005, p. 42). Indeed, because the Trafficking Protocol differentiates between worthy 'victims of trafficking' and unworthy willing sex workers, to stand any hope of being identified and assisted as a 'victim of trafficking' by the authorities in most countries, a migrant sex worker needs to demonstrate that she did not originally consent to sex work, and that she has undergone great physical suffering (Tomkinson, 2012, p. 59, O'Connell Davidson, 2010, p. 252). Suffering renders 'victims of trafficking' "innocent," but at the same time a lack of obvious physical suffering can entail pernicious consequences for those believed to have willingly taken up sex work. This is because, while condemning forced prostitution, anti-trafficking discourses offer nothing in the way of rights for the not so innocent "voluntary" prostitutes (Aradau, 2003, p. 3). The implication of this threshold of innocent victimhood is that the moment it becomes clear that migrant sex workers are not the 'pure and innocent' victims that anti-trafficking officials were looking for, that is, they may in fact be self-chosen sex workers, these migrant women become criminal outsiders who are intent on corrupting the nation. Thus, attention shifts from the 'victim' to the nation and ways to protect the nation from deviant migrant sex workers and the subsequent flow of illegal migration (Jeffrey, 2005, p. 41). This criminalization then renders migrant sex workers' experiences of violence and labour exploitation less visible, producing a tendency to discount the 
human rights of women involved in the sex trade and making it possible to deny them protection (De Shalit et al., 2014, p. 389).

The Trafficking Protocol initiates a victim-centered approach and as a result, signatory states construct themselves as missionary nations seeking to rescue others from their backwards and violent cultures. This construction, however, hides what is most vital in understanding the real basis of exploitation of migrant sex workers, which is not other cultures, but the Trafficking Protocol's own paternalistic response that puts migrant sex workers in a dangerous position (Jeffrey, 2005, pg. 42). This is because, the assumption of victimization that frames antitrafficking discourses is a reflection of patriarchal system that fails to see women's capability to do 'bad,' that is, to cross international border willingly and illegally. Thus, these discourses are based on problematic gender biases that create an understanding of women from the global South as trafficable helpless victims and countries of the global North as their heroic rescuers (Tomkinson, 2012, p. 59, p. 61, Soderlund, 2005, p. 77). These discourses of victimization and rescue are particularly evident in the resurgence of colonial narratives in contemporary moves to "save" non-western, racialized women. Consequently, gendered and racialized saving and rescuing crusades tend to treat all women, but immigrant women in particular, as naturally at-risk of engaging in acts that pose threats to themselves and society. Therefore, rather than understanding women's international migration as a product of social conditions such as, poverty, discrimination, and misogyny, they attribute risk to be an ontological characteristic of the women themselves, attached to both their gender and racial/cultural background. Thus, as a group, migrant women are constructed as "risk-bearing" rather than "rights-bearing," thereby contributing to state responses that are focused on security measures, risk assessment, and 
migration management rather than securing labour regulations and social protections (De Shalit et al., 2014, p. 389, p. 402).

The implementation of the Trafficking Protocol has occurred against a broader backdrop of tightened immigration policies and border controls in an attempt to manage migration. Following the September 11, 2001 attacks, policy makers identified migrants as potential security risks and concluded that migration needed to be effectively managed because national security was at sake. For this reason, trafficking, along with smuggling, have been increasingly defined as border security problems. Although trafficking falls within the mandate of various international agencies, as the next section reveals, the topic of border control in anti-trafficking interventions from a United Nations Office on Drugs and Crime perspective, generates responses that are more focused on crime control, border security, and managed migration, rather than the human rights of migrants (Miller and Baumeister, 2013, p. 17-18, O'Connell Davidson, 2006, p. 9).

\section{The Trafficking Protocol, Crime Control, and Security Measures: Further Implications for Migrant Sex Workers}

The Trafficking Protocol's approach to human trafficking is framed by a definition that is more focused on crime and security centering on reaching individuals at risk, rather than addressing the root causes of people's international migration, such as poverty and inequality. For this reason, the view of migrant women as 'risk-bearing' plays right into the security discourse that is now central to discussions of borders and international relations. The fact that the Trafficking Protocol is framed within the Convention on Transnational Organized Crime, and packaged with a Protocol on smuggling, reflects a preoccupation with 'illegal migration' and the supposed security threat posed by transnational organized crime as opposed to a concern with 
the human rights of migrants (Jeffrey, 2005, p. 41, Oxman-Martinez, Hanley and Gomez, 2005, p.14, O'Connell Davidson, 2006, p. 9). Taken together, the Trafficking and Smuggling Protocols assume a neat line of demarcation between oppositional categories - voluntary and consensual versus involuntary and non-consensual migration - an assumption that research shows to vastly oversimplify the systems and processes that facilitate migration in reality. More significantly however, the Trafficking Protocol expresses women's presumed greater disposition (along with children) to be deceived, above all into 'prostitution,' and their lesser disposition to be rational and active agents of migration (O’Connell Davidson, 2006, p. 9, Agustín, 2007, p. 40). In exemplifying women along with children, the Trafficking Protocol infantilizes women and perpetuates paternalistic and reactionary responses that propel the notion that women, like children, cannot make sound decisions. This assumption allows signatory states to argue for tighter security measures, particularly in border control and policing, in order to 'protect' women. However, as previously mentioned, these measures only end up penalizing women by driving migration and sex work further underground and making them more vulnerable to abuse and exploitation (De Shalit et al., 2014, p. 399, Jeffrey, 2005, pg. 43, Kapur, 2003).

Even if the Trafficking Protocol's definitional ambiguities and problems could be resolved, the Protocol would still remain a problematic instrument with which to address the issues concerning 'exploitation' in general and 'sexual exploitation' in particular. This is because, framed as it is within the Convention on Transnational Organized Crime, the interventions that flow from the Trafficking Protocol are only triggered by immigration offences, criminal violations, and/or organized criminal activity. As mentioned, this means that together, the Trafficking Protocol and Organized Crime Convention focus on an extremely limited and narrow part of the problem (O'Connell Davidson, 2006, p. 10). Indeed, the Organized Crime 
Convention is aimed at empowering governments to act in concert against gangs and mafias operating in the international drug trade, money laundering schemes, and illegal arms deals. While the attachment of separate Protocols to deal with smuggling and trafficking in humans is supposed to make a distinction between these purely criminal matters and the issue of migration, critics-including the former High Commissioner for Human Rights-Mary Robinson, the International Labour Organization (IOM), and the United Nations Children's Fund (UNIDEF) have pointed out that this distinction is not very clear (Jeffrey, 2005, p. 38).

The UNODC exemplifies this lack of distinction by noting that while the Organized Crime Convention establishes general measures against transnational organized crime, the two Protocols deal with specific crime problems. However, each Protocol must be read and applied in conjunction with the Convention. Article 37, paragraph 2, of the Organized Crime Convention provides that, in order to become party to one of its Protocols, a state must first be a party to the Convention. As such, the provisions of any Protocol to the Convention are to be "interpreted together with this Convention, taking into account the purpose of that Protocol" (UNODC, 2008, p. 8, p. 11). For this reason, because the Trafficking Protocol is purposely designed to be applied in concert with the Organized Crime Convention, the anti-trafficking efforts implement by signatory states will always be synonymous with war on international organized crime, defined as the movement of persons, weapons, or drugs that defy or circumvents legal boundaries and borders. Yet, by ignoring the reasons-and responsibilities-for why people begin their clandestine journeys and by making the stopping of smuggling and/or trafficking the top priority, the "get tough on traffickers and/or smugglers" framework further serves the ideological purpose of overlooking the fact that people's displacement is caused by economic, political, or social forces controlled by complex interactions of transnational corporations, nation states, and 
international bodies. This means that the priority of establishing law-and-order at the border, evident in anti-trafficking policies, further exacerbates the conditions that cause harm to migrants (Kempadoo, 2005, p. 39, Sharma, 2003, p. 58-59).

The government of Canada has acknowledged that prevention is a crucial component in responding to human trafficking. The Canadian government also recognizes the "importance of developing holistic strategies that address the root causes and risk factors that can lead to human trafficking and related forms of exploitation" (Government of Canada, 2012, p. 11). As previously mentioned there are a number of 'root causes' affecting international migration, especially for women. These may include: poverty, unemployment, globalization, gender-based discrimination, unequal employment opportunities, among other causes (GAATW, 2012a, p. 1112). The Canadian state is a leading proponent of free trade and greater trade liberalization, playing a highly visible role in negotiations at the World Trade Organization, and in the trade agreements of NAFTA and APEC. As a result, Canada has a direct hand in shaping policies at the global level that are pushing increasing numbers of women into migration (Thobani, 2001, p.30). However, the Canadian government's own enthusiastic support for globalization and trade liberalization policies are rarely recognized as being responsible for exacerbating the deteriorating socio-economic conditions in countries of the global South that contribute directly to the 'root causes' of migration and subsequent mass outflow of people in search of better economic opportunities (Lepp, 2002, p. 8). As Canada ignores the factors that drive international migration, it defines trafficking as the fault of Third World migrants and their communities. Through this process, Canada draws attention away from the reasons people migrate towards the 'holistic strategies' it has to put in place as a 'response' to this migration problem-originating elsewhere and of no obvious fault of Canada's global economic policies (Thobani, 2001, p. 25). 
In the Organized Crime Convention and Trafficking Protocol framework, the sex industry is perceived to be integral to the perpetuation of organized crime, specifically regarding drugs and the trafficking of people (O'Brien, Carpenter and Hayes, 2013, p. 405). For instance, in Canada between 2005 and 2009, several organized crime groups were identified by law enforcement for suspected involvement in human trafficking activities. Investigations confirmed that these groups were involved in the organized entry of Eastern European women for employment in escort services in Montreal and Toronto. Further, most of the individuals involved were linked to organized prostitution, with some identified as legitimate escort agency operators, while others, particularly in the Montreal area, were linked to massage parlour operations (RCMP, 2010, p. 12). The RCMP also maintains that exotic dance establishments have long been suspected of forcing trafficked women, in particular of Eastern European origin, to dance and prostitute. Yet the report highlighted contradictory evidence citing that several recent investigations were unable to substantiate the trafficking of foreign nationals in exotic dance clubs (RCMP, 2010, p. 19-20).

Despite the evidence indicating unsubstantiated connections between the sex industry and the perpetuation of organized crime, nation states are still devoted to endorsing that this association exists. Due to both the continuation of past narratives surrounding women's migration and sexuality and the current international climate concerning border controls, managed migration and anti-trafficking campaigns, governments have come to believe that the only way to both 'protect' vulnerable migrant women and curb transnational organized crime is through the eradication of the sex industry and the women who work in it (Kapur, 2003). Yet, the real concern for governments and policy-makers is not with 'protecting' women in the sex industry, but with preventing "innocent" women from becoming sex workers, and keeping 
"dirty" foreign sex workers from infecting the nation (Schaeffer-Gabriel, 2010, p. 154, Doezema, 2000, p. 37). For this reason, the existing definitions of, and analytical approaches to, the phenomenon of sex trafficking are constructed primarily from a law-and-order and moralistic standpoint (e.g., abolition of prostitution), rather than a human rights standpoint. Consequently, immigration policies in countries of the global North, like Canada and the U.S., are consistently discriminatory towards women and sex workers in particular (Timoshkina and McDonald, 2011, p. 19).

In the context of Canada, current immigration policies are discriminatory as they reflect the perception of women from developing nations as undesirable migrants who should be discouraged from entering or denied the opportunity to establish permanent residency. As the Canadian state privileges the entry of wealthy, well-educated, highly qualified young migrants, it also discourages others whose economic contribution is harnessed by the low-skilled job market or whose labour is largely confined to the domestic sphere. As a result, such immigrant preferences have not only class, but gender and race repercussions as well (Timoshkina and McDonald, 2011, p. 19-20, Dobrowolsky, 2011, p. 113). At the same time, states tend to implement restrictive immigration policies, such as sex worker visa bans, in an attempt to curb 'unwanted' migration while rhetorically broadcasting that it was for migrant women's 'protection.' Thus, with shrinking opportunities for legal migration, women become more likely to choose clandestine means of travel making them more inclined to seeking the assistance of traffickers and smugglers (O’Connell Davidson, 2010, p. 255, Timoshkina and McDonald, 2011, p. 20).

Many of the violations surrounding international migration stem from the convergence of structural trends related to globalization, inequality, the growth of clandestine migration 
networks, and the emphasis of the global economy on cheap labour costs (Avendaño and Fanning, 2013, p. 98-99). Yet through the Trafficking Protocol, anti-trafficking campaigns mistakenly shift the focus from masses of legal and illegalized migrants, who are exploited as cheap laborers due to the prevalence of globalized markets and lack of effective labour rights, to the 'duped' female migrants shuttled into underground prostitution and sex work. However, the Trafficking Protocol is not the only instrument determining problematic anti-trafficking policies on a global scale. As the next section reveals, in the last decade, the United States has also positioned itself as an equally significant force in the anti-trafficking arena (Schaeffer-Grabiel, 2010, p. 153, Soderlund, 2005, p. 67)

\section{The United States and the Trafficking Victims Protection Act of 2000}

By the late 1980s, stories about Latin American and Asian women illegally trafficked into Western Europe to work in brothels began to proliferate in the US news media. The collapse of communism in Eastern Bloc countries intensified the focus on trafficking as stories of Eastern Europeans sold into prostitution in Western Europe, the United States, and parts of the Middle East circulated widely (Soderlund, 2005, p. 71). As a direct result, shortly before the UN General Assembly adopted the Trafficking Protocol in October 2000, The U.S. passed the Trafficking Victims Protection Act of 2000 (TVPA). This Act increased penalties for trafficking-related offences committed in the U.S. It also contained important provisions intended to encourage anti-trafficking action by other governments. The U.S. justification for pressuring other governments to implement anti-trafficking policies is said to be based on human rights principles. However, in practice, the approaches that the U.S. has insisted other governments take often seem to inflict an unacceptable cost on human rights (Dottridge, 2007, p. 18). This is 
mainly due to the fact that, the approaches the U.S. has insisted other governments take are a reflection of U.S.'s own anti-prostitution policies and programs, which inform all aspects of its counter-trafficking initiatives. The U.S. anti-prostitution stance is a moral and ideological one with the U.S. regarding prostitution as inherently dehumanizing and not a legitimate form of work. Because of the refusal to address root social and economic causes of migration and exploitation (e.g., labour conditions of sex workers), this stance affects all elements of U.S. policy and has significant human rights implications for sex workers in general and migrant sex workers in particular, both in and outside the U.S. The U.S. position is characterized by an absence of meaningful labour and immigration law protections, and a focus on the moral harms of prostitution, justifying a legislated crackdown on women's sexuality and rights (Huckerby, 2007, p. 252, Soderlund, 2005, p. 82).

Diverging from the trafficking definition, the TVPA offers its own definition of trafficking making it synonymous with the exploitation of all women and girls in the sex industry and offering no category for unforced prostitution. While the Trafficking Protocol vacillates between referring to all commercial sex exchange as forced and making distinctions between voluntary and involuntary prostitution through the problematic implementation of consent, the TVPA offers no such distinction, thus rendering all women incapable of consenting and forever victims of the sex industry (Soderlund, 2005, p. 73). The TVPA also establishes a legal definition of 'severe forms' of trafficking that clearly distinguishes between 'sex trafficking' and trafficking of a person 'for labour or services.' The U.S.' abolitionist approach to prostitution informs all elements of the government's anti-trafficking agenda: from the assumption about the absence of consent in the definition of a trafficked person; to the legal and policy position that it will not fund projects or groups that promote, support, or advocate the legalization or practice of 
prostitution. Thus, the conflation of trafficking with sex work that occurred within U.S. antitrafficking policies created space for the mobilization of anti-prostitution sentiments and lobbies seeking to punish individuals or groups that refuse to conform to the U.S. definitions of prostitution as a criminal act (Huckerby, 2007, p. 231, Kempadoo, 2005, p. 51). Interestingly enough, this punishment is also prescribed in the United States' efforts to monitor the global anti-trafficking campaign through the evaluation and ranking of individual countries in their fight against trafficking (Roots, 2013, p. 26).

In addition to defining "severe forms of trafficking in persons," the TVPA generally expands U.S. activities internationally and in particular, mandates the Secretary of State to submit an annual report to Congress on severe forms of trafficking occurring in other countries. Essentially, through the TVPA, the U.S. assigns itself a leadership and policing role internationally in anti-trafficking, by authorizing itself to rank nations according to their status as importers or exporters of trafficking victims and to announce these rankings in an annual Trafficking in Persons Report (TIP report). The TIP report more or less functions as a global shaming tactic, while encompassing severe material implications for those countries that find themselves at the bottom of the ranking system (Soderlund, 2005, p. 76, Huckerby, 2007, p. 234). The first TIP report was issued in 2001. In the TIP report, countries are classified according to particular Tiers (Tier 1, Tier 2, Tier 2 Watch List and Tier 3) based on the extent to which the county is: a source, transit, or destination point for severe forms of trafficking; complies with the minimum standards set out in the TVPA; and has resources or capabilities to address severe forms of trafficking (Huckerby, 2007, p. 234-235). Within the Tier system, governments that fully comply with the TVPA's minimum standards are placed as Tier 1 and therefore classified as 'good nations' by the U.S. Countries that do not fully comply but are 
considered to be making significant efforts to do so are categorized as Tier 2. Countries on the Tier 2 Watch List are those that do not fully comply but are making significant efforts to do so, but have some particular cause for concern (e.g., the absolute number of trafficked persons is very significant or increasing). Tier 3 countries are those whose governments do not fully comply with the minimum standards and are not making significant efforts to do so (Huckerby, 2007, p. 235). According to the U.S. Department of State (2014),

...pursuant to the TVPA, governments of countries on Tier 3 may be subjected to certain restrictions on bilateral assistance, whereby the US government may withhold or withdraw non-humanitarian, non-trade-related foreign assistance. In addition, certain countries on Tier 3 may not receive funding for government employees' participation in educational and cultural exchange programs. Consistent with the TVPA, governments subject to restrictions would also face U.S. opposition to assistance (except for humanitarian, trade-related, and certain development- related assistance) from international financial institutions, such as the International Monetary Fund and the World Bank (p.44).

As a result, the Tier ranking system has led to misguided crackdowns on sex workers in countries seeking to secure a better ranking (Lerum et al., 2012, p. 90). By pressuring states to strengthen the power of police to conduct raids, U.S. anti-trafficking policies succeed in pushing the sex industry further underground and into less safe and more exploitative areas (Jeffrey, 2005 , p. 34). Yet, for governments that strive to be classified as a 'good nations' by the United States or those that would like to avoid being labeled a Tier 3 country and thus, punished accordingly (e.g., through military aggression, economic embargos, cuts in development aid, etc.) intervention in the sex sector according to U.S. anti-trafficking policy, is a quick and easy fix (Kempadoo, 2005, p. 49).

The Trafficking Victims Protection Reauthorization Act (TVPRA) of 2003 added to the original law (TVPA) a new requirement that foreign governments provide the Department of State with data on trafficking investigations, prosecutions, convictions, and sentences in order to 
be considered in full compliance with the TVPA's minimum standards for the elimination of trafficking (Tier 1) (U.S. Department of State, 2014, p. 45). Yet what the U.S. completely disregards is the fact that figures on trafficking remain extremely inaccurate, and time and again it is heard that "numbers are not available" or that no statistics exist on the matter (Kempadoo, 2005, p. 46). Even the UNODC in its latest Global Report on Trafficking in Persons (2014) noted,

at present, there is no sound estimate of the number of victims of trafficking in persons worldwide. Due to methodological difficulties and challenges associated with estimating sizes of hidden populations such as trafficking victims, this is a task that has so far not been satisfactorily accomplished. The question of the magnitude of the trafficking problem-that is, how many victims there are-is hotly debated as there is no methodologically sound available estimate (p. 30).

It is additionally important to point out that, akin to the basis for the TIP reports, the UNODC's report is based on a compilation of human trafficking information provided by individual governments, and not accumulated first hand by the UNODC ${ }^{7}$. The United States' arbitrary use of evidence and the unsystematic collection of data have led analysts to conclude that some nations will be punished only on the basis of insufficient evidence. According to Kamala Kempadoo, Iran along with many countries with majority Arab and/or Muslim populations, such as Indonesia, the United Arab Emirates, Afghanistan, Lebanon, Qatar, Turkey, and Saudi Arabia, were placed in Tier 3 in 2002, thus defined by the U.S. State Department as sanctionable. This strongly suggests a link in the 2002-2003 U.S. state policies on trafficking with its war on terrorism that targeted the Arab and Muslim nations (2005, p. 45). Indeed, over a decade later, with the United States' foreign policy still strongly centered in the Middle East, the latest 2014 TIP report reveals that all of the countries listed above have not made it past the Tier 2 ranking

\footnotetext{
${ }^{7}$ See page 17 "Methodology" of the United States of America (U.S.) Department of State Trafficking in Persons Report 2014.
} 
with Iran still in Tier 3 joined by new dissenting states Syria and North Korea (U.S. Department of State, 2014, p. 209, p. 366, p. 231).

In 2004 Canada was demoted to a Tier 2 country in the U.S. ranking system for its failure to fully address human trafficking concerns according to U.S. government standards. Since then, pressure has been exerted by the U.S. government onto the Canadian government to institute more effective anti-trafficking policies and tighten border controls (RCMP, 2012, p. 16, Jeffrey, 2005, p. 38, Roots, 2013, p. 27). In this respect, several countries, including the United States, have accused Canada of being a 'jumping off point' for terrorists and of being too lenient in its acceptance of immigrants and refugees. Similarly, a paper by the Center of Immigration Studies in Washington also suggested, 'Canada is the 'weak link' in America's defense against terrorist operations." Beyond the actual ranking system, criticisms of Canada's immigration policies are also evident in the annual TIP reports, which demonstrate yearly-reinvigorated U.S. pressure to toughen all aspects of its approach to trafficking. Year after year, the reports have recommended intensification of Canada's efforts to investigate and prosecute human trafficking offenses, increase proactive investigation techniques, and improve coordination between national, provincial, and international law enforcement. Although the latest TIP report has not deviated from these recommendations, new ones have been added urging Canada to vigorously investigate and prosecute Canadian child sex tourists and improve trafficking data collection, particularly regarding victim identification and assistance (Roots, 2013, p. 27, U.S. Department of State, 2014, p. 125).

Canada's border control strategy was further criticized in the 2003 U.S. Department of State Report on Human Rights. The report claimed that a number of Canadian cities served as hubs for criminal organizations involved in human trafficking. According to the report, Canada 
is targeted by various criminal organizations as a result of its lenient immigration laws, benefits available to immigrants, and the proximity to the U.S. border. Due to the criticism and pressure stemming predominantly from the U.S., Canada began placing greater emphasis on security and renegotiated a number of border control measures with the United States, including increased security checks for refugee determination process, extended detention of migrants unable to prove their identity, intensification of deportation, and harsher penalties for using false documents (Roots, 2013, p. 27). On June 6, 2012, the Canadian federal government launched the National Action Plan to Combat Human Trafficking (National Action Plan), which outlined federal anti-trafficking efforts under the ' 4 Ps'-prevention of the crime, protecting its victims, prosecuting offenders and building partnerships, both at home and abroad (Public Safety Canada, 2013a, p. 4). The National Action Plan included, for example, measures to improve the protection of vulnerable foreign nationals, including female immigrants who arrived alone in Canada, from forced labour and sexual exploitation at an early stage (Government of Canada, 2012, p. 15). Many more efforts have also been taken to demonstrate Canada's efforts in combating human trafficking, including the 2005 implementation of section 279.01 through 279.04 of the Criminal Code in order to create three new offences relating to trafficking in persons, and of course, the 2012 migrant sex worker ban as a way to prevent the sex trade from accessing the Temporary Foreign Worker Program in order to "better protect vulnerable persons who are at risk of being trafficked into Canada" (UNODC, 2008, p. 99, Government of Canada, 2012, p. 15).

The international pressure placed by global anti-trafficking discourses, and specifically by U.S. policies, to criminalize sex trafficking have had vast repercussions for migrant sex workers and women looking to migrate to Canada in the hopes of creating a better life for 
themselves. The paternalistic policies embedded in global trafficking discourses and in U.S. policies, have resulted in a suppression of migrant sex work, factors that will be apparent in the next section focusing on the Canadian sex trade, particularly where it pertains to the exotic dance industry, human trafficking policies, and the making and unmaking of Canada's exotic dancer visa. 


\section{CHAPTER III}

\section{THE CASE OF CANADA: EXPLORING THE INTERSECTIONS BETWEEN MIGRANT SEX WORKERS, THE ANTI-TRAFFICKING REGIME, AND THE TEMPORARY FOREIGN WORKER PROGRAM}

\section{Exotic Dancing in Canada: a Brief History}

Exotic burlesque dancing, or strip tease, made its debut in Ontario during the 1950s. Showgirls erotically titillated theatre audiences through their costume, movements, and seductive disrobing. Yet, during this time, showgirls and spectators remained physically separated throughout the performances with showgirls on stage and audience members in theatre seats. The 1960s and 1970s saw the gradual demise of burlesque performances in theaters and its movement towards smaller venues such as clubs and bars. This movement also influenced the removal of the g-string and acceptance of total nudity in clubs while allowing dancers to move off the stage and onto the main floor of clubs. With access to the main floor, dancers began performing "table" or "lap" dances in close proximity of a personal customer. Lap dancing refers to the practice of nude or near nude women straddling a seated patron and more or less simulating sex. In principle, strip club patrons are prohibited from touching the dancers. In practice however, they do. This is because bars that offer direct access to women's bodies draw more patrons than those that do not. Market forces, as personified by bar owners, then pressure women to 'consent' to physical contact. As a result, the advent of lap dancing exposed women to uninvited and unwanted physical contact with predominantly male customers (Macklin, 2003, p. 468).

In Ontario, by the late 1970s showgirls were either working in bars or strip clubs, paid based on the number of shows they preformed, or they were touring a circuit of clubs where they preformed for a set number of shows as featured performers (STAR, 2004, p. 5). Private "champagne" or VIP rooms came on the scene starting in the 1980s and provided a secluded 
place where a dancer could perform table and lap dances away from the view of other patrons and bar owners. Table and lap-dances in VIP rooms each came with a set fee per song and the possibility of additional tips based on the customer's satisfaction with the performance (STAR, 2004, p. 5, Timoshkina, McDonald and Wellesley Institute, 2009, p. 33-34). However, it requires little imagination to recognize that the risk of harm to the dancers in the form of non-consensual contact can only be exacerbated in circumstances where the patron and the performer are secluded from observation. The curtain or room shielding what happens on the other side of it from public and, therefore judicial scrutiny, is precisely what heightened a dancer's vulnerability to sexual harassment, assault and pressure to perform extra sexual contact (e.g. oral sex, vaginal intercourse, etc.) (Macklin, 2003, p. 470, STAR, 2004, p. 9).

As the Canadian economy weakened in the early 1980s, more women were pushed into low skilled and poorly paid service sector jobs. The exotic dancing industry then began attracting more female workers willing to accept "shift pay" rather than demanding a weekly wage. Strip club owners justified shift pay on the grounds that dancers were now earning money directly from customers by performing private dances (STAR, 2004, p. 5). The final change in the exotic dancing scene came in the 1990s when shift pay gradually disappeared and dancers started working as freelance entertainers, which meant that they were not paid by the clubs but rather had to pay the clubs for the right to use the premises. In most clubs dancers were charged various fees, such as, bar fees, disk jockey fees and/or VIP room fees, for the privilege of dancing in a club.

By the early 1990s not only did exotic dancers lose control over their working conditions and saw them rapidly deteriorate, but they also became fully dependent on customers for income and were under constant pressure to perform sexual "extras" as a way of earning more money 
and supplementing their incomes. Even though the work expectations and work environment of exotic dancers, and specific threats to their health and safety are addressed in provisions of federal and provincial legislation as well as some municipal by-laws, official disinterest in enforcing these laws have rendered lap dancing and other similar activities effectively available (STAR, 2004, p. 13, Macklin, 2003, p. 470). As fewer and fewer Canadian women were willing to work under these unrestrained conditions, and with the increase in the number and size of strip clubs, foreign women were brought into Canada to fill what strip club owners described as a "labour shortage" (STAR, 2004, p. 6, Timoshkina, McDonald and Wellesley Institute, 2009, p. 33-34).

The following section provides an overview of the making of Canada's Temporary Foreign Worker Program (TFWP), established for the purpose of filling acute labour shortages when Canadians and permanent residents were not available (Fudge and MacPhail, 2009-2010, p. 11). The establishment of the TFWP allowed for the creation of the exotic dancer visa, which up until its absolute elimination in 2012, was used to legally permit foreign women to work in Canada's sex industry. As one preceded the other, both will be discussed as a means of forming the groundwork for analyzing Canada's anti-trafficking policies where they concern the migrant sex worker ban.

\section{The Temporary Foreign Worker Program}

Strippers as Temporary Workers: Origins of The Exotic Dancer Visa

In the past, immigration has been an instrument of nation building, with Canada treating immigrants as "citizens in waiting." Membership into the nation-state is a public good that is distributed by Canada to migrants via permanent residence or 'landed immigrant' status. Permanent residence creates a qualified entitlement to enter and remain in Canada, and it is also 
the precursor to legal citizenship, which in turn confers a virtually unqualified right to enter and remain in Canada. Previously immigrants and most refugees in Canada who acquired permanent resident status were then eligible to apply for Canadian citizenship after three years (Siemiatycki, 2010, p. 60, Macklin, 2003, p. 465). Most recently however, with Canada's increasingly heavy reliance on foreign labour, it has become clear that Canada has moved away from a project of relatively inclusive nation-building, based on permanent pathways to citizenship, towards a model of restricted access to citizenship and the extensive use of temporary foreign workers (TFWs) (Baxter, 2012, p. 7, Root et al., 2014, p. 14).

Historically temporary migration programs in Canada predominately included the recruitment of foreign domestic workers and farm labourers. The recruitment of foreign domestic workers was closely linked to Canada's nation-building efforts and designed to ensure women of the "right" national and racial stock were permitted entry and entitled to long-term settlement. The first groups of women of colour who entered Canada in 1955 were denied the right to permanent residence. The Canadian state justified its discrimination on the basis of the women's supposed "sexual licentiousness" and continued to build its "White" settler state. Programs specifically designed to recruit farm labourers were initiated in 1966 through bilateral agreements with Mexican and Caribbean governments for the purpose of providing seasonal employment in agriculture (Hari, McGrath and Preston, 2013, p. 16). In place of these diverse programs, the Canadian federal government introduced the umbrella Non-Immigrant Employment Authorization Program (NIEAP) in 1973. The NIEAP signaled a shift in Canadian policy from immigration for permanent settlement to temporary foreign workers. The NIEAP also signaled a shift from temporary programs that targeted specific sectors and occupations (e.g., seasonal agricultural workers and domestic workers) to a general program that more 
efficiently recruited and monitored increasing numbers of foreign workers for a wide array of occupational "labour shortages" in Canada. The core characteristics of the NIEAP continue to form the structure of Canada's contemporary TFWP. (Hari, McGrath and Preston, 2013, p. 1617, Fudge and MacPhail, 2009-2010, p. 8, p. 11).

From the start, the NIEAP also placed restrictions on migrants who intended to work in Canada. For instance, workers admitted under the NIEAP were only entitled to legally stay in Canada for the duration of their authorized employment. Migrant workers were no longer allowed to apply for work permits from inside the country, and they had to leave Canada in order to apply to change their immigration or employment status. Work permits also assigned temporary foreign workers to a particular employer and stipulated their occupation, residence, and length and terms of employment (Fudge and MacPhail, 2009-2010, p. 7). These restrictions continue today within the contemporary TFWP. Additionally, once employed in Canada, depending on the province of residence, temporary workers usually have limited access to the public benefits available to most permanent residents and citizens, such as public health care and income support, although they do pay taxes and various employment based-deductions (Macklin, 2003, p. 465-466). As a result, many commentators argue that not only do temporary foreign worker programs create an entire stratum of vulnerable workers, but also those that particularly target low-skilled workers, are exploitative (Lenard and Straehle, 2010, p. 283, Siemiatycki, 2010, p. 62).

The TFWP is jointly administered by Citizenship and Immigration Canada (CIC), Employment and Social Development Canada (ESDC, formally known as Human Resources and Skills Development Canada, HRSDC), and the Canadian Border Services Agency (CBSA) (Nakache and Kinoshita, 2010, p. 12). Employers seeking to hire foreign nationals to work 
temporarily in Canada must first obtain an employment authorization, known as a Labour Market Impact Assessment (LMIA). Issued by ESDC, the LMIA considers whether the wages offered to the foreign national are consistent with the prevailing wage rate for the occupation, whether the working conditions meet generally accepted Canadian standards, and whether the employer has made reasonable efforts to hire or train Canadian citizens or permanent residents (Fudge and MacPhail, 2009-2010, p. 9, p. Faraday, 2012, p. 29). Once in receipt of a positive LMIA, the foreign national must apply to CIC for a work permit. CIC is primarily concerned with whether the potential TFW meets the job qualifications (e.g., if applying for an engineer position if they have an engineering degree, required job experience, designations, etc.), and if he or she will leave Canada at the end of their authorized stay. It is then the CBSA officer at the port of entry who has the final say on whether an individual can enter Canada. Thus, a positive LMIA and permission to work in Canada are not determinant of admission, since the CBSA officer must still review all immigration, identity, and work-related documents before printing off the actual work permit and allowing the person to enter the country (Nakache, 2010, p. 46). Yet in practice not all TFWP have followed this precise method for obtaining a work permit in Canada. Particularly, the exotic dancer visa is the product of a 1978 loophole in Canadian immigration law exempting foreign exotic dancers from the employment validation process conventionally required to issue a work permit (Macklin, 1999, p. 25-26).

In regards to the origins of the exotic dancer visa, following the establishment of the NIEAP, Canadian and American women began engaging in an informal cross-border stripper exchange program. As a result of this cross-border movement, instructions were put in place to issue employment authorizations to exotic dancers without validation from then Human Resources Development Canada (HRDC) based on exemption E-99 (reciprocity). Exemption E- 
99 also provided legal authority for dispensing with the requirement of applying and obtaining a work permit overseas in accordance with Immigration Regulations: s. 20(5)(e)(iii). By virtue of this special exemption, strippers with a job offer from a Canadian employer could arrive at a Canadian port-of-entry, apply for and receive a work permit on the spot without any detailed scrutiny of the circumstances behind the demand for their services. Thus, the exotic dancer visa was originally implemented to allow women from the United States to work as exotic dancers in Canada (McDonald et al., 2002, p. 6-7, Macklin, 2003, p. 467).

\section{Trafficking in Women by way of The Exotic Dancer Visa: Partial Truths and Complete Consequences}

As the 1970s and 1980s saw the rise of the exotic dancer visa along with the cross-border movements of Canadian and American women seeking employment in one another's' sex industries, the 1990s witnessed the rapid decline of Canadian women willing to work in the sex trade and the sudden increase of migrant workers taking on this undesired reproductive labour (Macklin, 2003, p. 467, Timoshkina, McDonald, and Wellesley Institute, 2009, p. 33, Kapur, 2003). As mentioned, the increase in migrant women was the result of a perceived "shortage" of dancers in the Canadian labour market. The owners of strip clubs complained that due to the stigmatized nature of stripping, few Canadian women were going into the business. Thus, foreign workers had to be brought in to keep the industry going. Canadian dancers however, argued that this "shortage" was due to the changing nature of the industry, which, as previously explained, had evolved from burlesque entertainment to part of an unregulated sex trade (Timoshkina, McDonald, and Wellesley Institute, 2009, p. 33). Yet both these factors can be viewed as furthering the decline of the Canadian exotic dancer. As noted by Audrey Macklin (2003), the "macro-geographical shift in source countries for strippers in the 1990s coincided with a micro- 
geographical shift in the Canadian job site, which descended from the stage to the table-top to men's laps" (p. 468). This degeneration in working conditions bolstered the cultural stereotype of strippers as sexually available to any customer, or to any man whether in or outside the strip club, contributing to their stigmatization and risk of harassment and assault (STAR, 2004, p. 11). As a result, stripping became culturally stigmatized as a low-skilled 'deviant' occupation, with the women who do it commonly perceived as thinly disguised prostitutes. As Canadian women were able to opt out of the industry, thus entered the recruitment of Eastern European, Asian, and Latin American women from poorer countries, with fewer options and less information about the prevailing conditions of the occupation (Macklin, 2003, p. 480, p. 473).

The regression of Canadian exotic dancers coupled with an apparently 'insatiable appetite' in Canada for commercial sex, caused the demand for strippers to exceed supply therefore, providing the "pull" factor for migrant women in search of better economic opportunities (Macklin, 2003, p. 471, Public Safety Canada, 2013, p. 4). As mentioned before, the growing number of women migrating from specifically Eastern Europe and Russia was largely due to massive job losses and abject poverty resulting from economic restructuring in the former Soviet Union. These deteriorating economic conditions provided the "push" factor for Eastern European and Russian women to search for alternative means of subsistence (McDonald et al., 2002, p. 68, Public Safety Canada, 2013, p. 4). Also as previously mentioned, "push" factors are also argued to be caused by the ongoing destructive effects of globalization, including the imposition of structural adjustment policies and international trade that squeeze national economies, particularly in countries of the global South. These critical factors have resulted in the growing economic disparities between North and South, and the feminization of migration, which coincidentally, "push" Asian and Latin American women to search elsewhere for more 
viable economic options (Lepp, 2002, p. 5). Thus the limited restrictions placed on obtaining an exotic dancer visa resulted in a legal immigration opportunity for foreign women who wanted to come to Canada in search of a better economic future.

For migrant women the exotic dancer visa became a feasible legal way to come to Canada and work in order to further their life goals. Indeed, according to a study on migrant sex workers in Canada, one sex worker service provider stated that the three main reason migrant women got involved in sex trade work in Canada was to: $i$ ) support family back home, ii) to earn extra income, iii) to purchase a large item like a house or a car (McDonald et al., 2002, p. 22). As a result, most migrant women did not plan on staying and working in the sex trade for very long, but instead, planned on making enough money and going back home (McDonald et al., 2002, p. 22). However, with the increasing amounts of foreign women searching for work internationally, strip club owners and so called immigration 'brokers' used the employment validation exemption for exotic dancers to their advantage by spawning a burgeoning and highly profitable racket of importing migrant women (Macklin, 1999, p. 25- 26). Consequently, as foreign exotic dancers had traditionally come to Canada from the United States, by the late 1990s, when far greater numbers were arriving from Eastern Europe, concerns about human trafficking began to emerge (Barnet, 2007, p. 5). In this respect, international anti-trafficking narratives provided a discourse of presumed sexual enslavement and exploitation by way of the exotic dancer visa to counter the rhetoric of "employment opportunity" and "economic benefit" which normally shapes the discussions surrounding temporary foreign workers in Canada (Macklin, 1999, p. 26).

Supporting the case for the global trafficking in women narrative was the process associated with bringing foreign women into the Canadian sex industry. The process can be 
described as follows. Canadian club owners negotiated with 'brokers' who guaranteed delivery of migrant sex workers. This contemporary trade in women using the exotic dancer visa was facilitated by an extensive, yet loosely based, network of agents, smugglers, and yes, sometimes traffickers based both in Canada and abroad. Within this process, these individual immigration 'brokers' would work in conjunction with Canadian club owners to unite global supply with Canadian demand. Then, using job offers issued by the clubs, migrant women could obtain work permits at the port-of-entry (Macklin, 2003, p. 471). Yet, because of the employment validation exemption, no assessments were conducted on their place of employment, prevailing wage rate, working conditions, or demand for their services. Consequently this left the Canadian government with a rather limited understanding of how loosely employment standards were enforced, if at all, and the abysmal working conditions migrant sex workers were forced to endure as a result (STAR, 2004, McDonald et al., 2002, p. 51). Thus, Canada's employment validation exemption for exotic dancers provided a legal circuit for making the connection between legal sex work, exploitation, and trafficking (Macklin, 2003, p. 471).

Once employed in Canada, further supporting the case for the global trafficking narrative was the fact that typically, migrant sex workers knew little of Canadian law, labour standards, or local expectations. Most arrived with a sizable debt-burden owed to the broker or club owner who paid for their travel and sponsored their work visas or immigration (STAR, 2004, p. 6). Migrant women entering on the exotic dancer visa were also at times deceived about the nature of the work required of them, and therefore, often forced to perform tasks they would otherwise refuse. For example, before arriving in Canada a woman may have expected to dance but not strip or strip but not lap dance; or lap dance, but not perform oral sex, etc. (Macklin, 2003, p. 474). In some extreme cases migrant women were completely deceived by being told they 
would be doing different jobs such as, waitressing, domestic service, modeling, singing/entertaining, or professionally dancing once in Canada (McDonald et al., 2002, p. 24). Yet, as their work permits tied them to one employer they were not eligible to work anywhere else but the club that had hired them, and were thus dependent on the club owners and expected to comply with their demands (Timoshkina, McDonald, and Wellesley Institute, 2009, p. 35, STAR, 2004, p. 6). Frequently, the foreign women brought to the clubs claimed to have no previous experience working in any aspect of the sex trade in their countries of origin. Yet, once in Canada, the women would often receive no training or preparation for their job (McDonald et al., 2002, p. 50, p. 57, Macklin, 2003, p. 471). As a consequence, migrant women would often have little, if any knowledge, about the sex industry and its less savoury characteristics, leading to confusion about the status of prostitution in Canada and what legally fell under the rubric of exotic dancing (McDonald et al., 2002, p. 66, p. 25).

In regards to the actual worksites, due to the changes that took place in the exotic dance industry in the early 1990s, the financial arrangements for migrant sex workers involved paying daily fees to the club and the disc jokey, plus special fees for the VIP rooms. These fees could easily exceed $\$ 70.00 \mathrm{CAD}$ a day. Adding to the trafficking narrative in terms of exploitation, at times some women would have to pay extra fees for being late to work or any other creative charge strip club owners could think of (Macklin, 2003, p. 473, McDonald et al., 2002, p. 49). Although it was true that migrant sex workers were making more money than they ever made in their country of origin, the industry operated in a way that paid them just enough money to keep them in business. As a result, the ongoing charges served to disadvantage migrant women because it prevented them from saving money or paying down their debts, impelled them to work 
longer hours and most important, helped to ensure their attachment to the industry (McDonald et al., 2002, p. 47-49).

According to the RCMP, police investigations confirmed that although there were exotic dance establishments that would not condone the offer of extra sexual services on the premises, some managers may have "turned a blind eye" to illicit activities taking place in the club. As a result, some of the migrant women working in strip clubs were found to have offered sexual services in exchange for money (RCMP, 2010, p. 11-12). In this case, as most migrant sex workers were not paid a set wage by the clubs, they had to earn their income by charging individual patrons for lap dances, table dances, or extra sexual acts. As a result, the women's earnings depended on how much they could 'hustle' and what they were willing to do to make enough money over and above their daily 'fees.' The pressure to perform extra sexual services also stemmed from the migrant women's escalating debt owed to the broker or club owner who paid for their travel, and was often backed up by threats or actual physical/sexual coercion. In some cases agents demanded hefty daily fees, or may have forced migrant women to hand over all their earnings for 'safekeeping' or with the (false) assurance that they would send the money back home for them. The women may have also believed that by handing over all their earnings they were working off debt, yet the debt never diminished (McDonald et al., 2002, p. 24, Macklin, 2003, p. 473).

In light of the above circumstances, it is apparent that once employed in Canada, migrant sex workers were routinely subjected to labour exploitation, with some women finding themselves in various situations of trafficking (Timoshkina, McDonald, and Wellesley Institute, 2009, p. 34). As previously mentioned however, the exploitative conditions migrant sex workers were forced to endure were the result of an overall lack of effective employment standards 
enforcement within the exotic dance industry, which not only fostered this malignant abuse towards the migrant women, but also allowed it to continue. For example, in their study of health and safety standards within the exotic dance industry in the province of Ontario, the Sex Trade Advocacy and Research (STAR) Project noted that research with exotic dancers in southern Ontario and a review of the federal, provincial and municipal acts, codes, and policies lead to the conclusion that exotic dancers had been over-looked in the formation and implementation of policy (2004, p. 26). Likewise the Metropolitan Action Committee on Violence Against Women and Children (METRAC) stated that because sex work is not recognized as legitimate work by the government of Canada, the definition of work place harassment does not pertain to exotic dancers who might experience violence/harassment while engaged in sex work (2008, p. 7). Even though the Criminal Code of Canada ensures all residents' protection from harassment and physical and sexual assault, exotic dancers consistently conveyed a strong reluctance to contact police when they were victims of a crime. According to STAR, exotic dancers' experiences with police were more likely to reflect disrespect, discrediting, and disbelief regarding their claims. The "it's just a whore" mentality of some police officers and/or the belief on the part of sex workers that this would be the response to their complaints, resulted in few seeking assistance (STAR, 2004, p. 24, STAR, 2006, p. 26).

In Ontario there are five types of provincial legislation that are applicable to sex workers in exotic dance clubs. These include: labour legislation regarding occupational health and safety, workers' compensation for injuries that occur while at work, minimum standards in employment legislation, crime victim compensation legislation, and provincial highway traffic legislation (STAR, 2006, p. 17). The problem however, is that such employment related regulations are not uniformly or adequately applied within the exotic dance industry. In some cases this is because 
the applicability of the legislation to strip clubs or exotic dancers is unclear. This is the case with respect to legislation that addresses rights and responsibilities of employers towards their workers. Since strip club owners typically do not employ exotic dancers (as most operate as independent contractors), but permit them to work on their premises, they generally do not qualify for protections afforded to employees and are thus excluded from Acts or sections of Acts which use the employer-employee terminology (STAR, 2004, p. 21, STAR, 2006, p. 17). In the case of migrant sex workers, as their work permits tied them to one employer and one place of employment, they did not function as independent contractors (STAR, 2004, p. 6). Consequently, this habitual lapse in the application of employer-employee related legislation within the exotic dance industry left them vulnerable to labour related abuses at the hands of employers without properly enforced recourse.

The Ontario Occupational Health and Safety Act requires the formation of a health and safety committee comprised of owners and worker representatives. This committee is responsible for overseeing health and safety issues in the workplace, including receiving and dealing with complaints. Yet, because of the mobility of Canadian exotic dancers and the free-lance nature of their work, strip clubs do not have such committees and consequently no one is mandated to address health and safety issues related to work condition (STAR, 2004, p. 24). As a result, the establishments within which migrant women were employed in were not subjected to health inspections (with the exceptions of the kitchens only in the strip club) therefore, most were breeding grounds for poor environmental working conditions. According to the McDonald et al., study, the migrant women interviewed felt their places of employment had less than ideal environmental conditions, with the authors themselves adding that the working conditions were "appalling" because some of the very basic standards for cleanliness, safety, and heating were 
not met (McDonald et al., 2002, p. 51 p. 67). Moreover, the authors also contended that these appalling conditions further illustrated the lack of importance/worth ascribed to women in the sex trade. The only concerns many owners and agents had was profitability. As long as the migrant women continued making money, everything else was peripheral (McDonald et al., 2002, p. 52). There needed to be an alternative system to that ascribed in this Act for creating occupational health and safety committees within strip clubs. STAR for example, proposed the establishment of regional committees with representation from club owners, through organizations such as the Adult Entertainment Association of Canada (AEAC), and sex workers, through sex worker advocacy groups like STAR, to deal with occupational health and safety issues for clubs (STAR, 2004, p. 24). Yet, the reluctance on the part of the federal or provincial governments to implement more effective health and safety regulations additionally exemplified the lack of importance/worth ascribed to the women in the sex industry and allowed for the conditions that fostered abuse to flourish.

Despite the obvious gaps in labour related policy within the sex industry, in 1997 it came to the attention of the federal government that, because of the use of the exotic dancer visa, migrant women were being routinely exploited in the strip clubs, with many finding themselves in various situations of trafficking (Timoshkina, McDonald, and Wellesley Institute, 2009, p. 34, Barnett, 2007, p. 5). In particular, at that time the media seized on the special work visa for exotic dancers as part of a wider story about trafficking in women. As a result, the state's facilitative role in importing foreign women destined for the Canadian sex trade caused considerable embarrassment for the government. Yet, the Canadian government did not react by abolishing temporary work visas for exotic dancers (Macklin, 2003, p. 474). As the next section reveals, before the outright banning of the sex industry from the TFWP in 2012, there were small 
devolutionary steps taken by the Canadian government in an attempt to minimalize the international perception that Canada's immigration policies facilitated the sexual exploitation of migrant women and human trafficking (Roots, 2013, p. 27, Gordon, 2006). These steps however, came at a cost to the migrant women who not only wanted to work in Canada, but to do so legally.

\section{Prohibiting Migrant Sex Work: The Unmaking of Canada's Exotic Dancer Visa}

When controversy first erupted in 1997, the government indicated its intention to revoke the labour validation exemption, re-introduce the job validation requirement, and compel migrants to apply for work visas from Canadian embassies abroad instead of at the port of entry. Citizenship and Immigration Canada insisted "the entry of exotic dancers should not be facilitated in any way different from that for temporary workers in other occupations." Treating exotic dancers the same as any other temporary foreign worker would have required the Canadian government to examine the circumstances behind the demand of foreign dancers, the nature of the exotic dancing industry, and the impact of foreign workers on wages and working conditions (Macklin, 2003, p. 476-477). Therefore, the government would have had an opportunity to ameliorate unfavourable working conditions in the strip clubs, ensure that labour related legislation was being properly applied, and overall improve protections for migrant sex workers within the temporary foreign worker program. This however, never happened. Instead of actually requiring strip club employers to prove that they were offering acceptable wages and working conditions or that adequate efforts were being made to recruit Canadian women, Human Resources Development Canada "papered over the cracks" in the policy by issuing a letter stating: 
Please be advised that Human Resources Development Canada does not foresee employment opportunities for Canadian citizens and permanent residents being adversely affected by the current level of foreign exotic dancers entering the country on a temporary basis.

This letter essentially eliminated the need for case-by-case consideration and upheld the employment validation exemption for obtaining an exotic dancer visa (Macklin, 2003, p. 477).

However, the aspect of the policy that did change was that applications for exotic dancer visas would now have to be made at Canadian embassies abroad and instead of at the port of entry. Under these circumstances, Citizenship and Immigration Canada began implementing a number of unofficial measures to ensure that few applicants for exotic dancer visas were actually accepted. These measures included refusing visas because of lack of work experience (e.g., only experience in topless dancing when the position required nude dancing) and also because it was found that applicants were unlikely to return home after their work visa expired. Using the Canadian High Commission in Bucharest, Romania as an example, between July 1997 and July 1998, immigration officers rejected 106 of 195 visa applications. By March 1999, only eight applications were submitted, and none were approved (Barnett, 2007, p. 5, Macklin, 2003, p. 478).

When the link between the exotic dancer visa and trafficking in women first captured media attention, intergovernmental correspondence revealed a concern that the entry of foreign strippers was "incompatible with Canada's highly publicized opposition to the trafficking in women for the purpose of sexual exploitation." Once the visa had been partially modified, a CIC spokesperson insisted that "the logic behind that is really to protect the women," presumably from sexual exploitation (Macklin, 2003, p. 482-483). By circumventing the lawful entry of foreign women employed in the sex trade, Canada avoided the embarrassment of propping up the exotic dance industry and played into the renewed global interest in an anti-trafficking law-and- 
order agenda, but only at the cost of consigning migrant women to the most unregulated market of all: the underground market. Limiting women's' opportunities for migration does not reduce trafficking or smuggling, but merely drives these processes further underground, intensifying the potential violence and abuse to which women are subjected, and increasing the profits that can be derived from facilitating unlawful cross-border movements, contract violations, forced labour, and exploitative practices (Macklin, 2003, p. 484, Lepp, 2002, p. 8). For example, in the study conducted by McDonald et al., (2002) on migrant sex workers in Canada, the authors noted that once the migrant women overstayed their visas and became illegal, those who facilitated their migration to Canada (club owners, agents, traffickers, etc.) could increase control over their activities (p. 42). The study also found that being undocumented seriously limited the women's choices especially in terms of their work because they could not find jobs. It also pushed them deeper into the sex trade where they might work in clubs and studios that were more likely to be “dirty"'(McDonald et al., 2002, p. 66).

As previously mentioned, Canada was heavily involved in the negotiations leading to the adoption of the Trafficking and Smuggling Protocols, with the participation of representatives from the Department of Foreign Affairs and International Trade, Status of Women Canada, and the Department of Justice Canada. Canada was also among the first nations to sign (December 2000) and ratify (May 2002) the Protocols, thereby formalizing its commitment to combating human trafficking and smuggling (Oxman-Martinez, Hanley and Gomez, 2005, p. 9). Although Canada was faced with an insurmountable amount of international pressure, especially from the U.S., to implement tougher anti-trafficking policies (and border security policies), the issues

\footnotetext{
8 According to the Macdonald et al., (2002) study, the establishments that housed sex-related activities were usually characterized as either "clean" or "dirty." These terms were applicable to both the massage parlours and strip clubs where women interviewed were employed. Such terminology related to the level of sexual activity taking place within these operations, the meaning of which varied depending on the individual (p. 45).
} 
surrounding the exotic dancer visa did not resurface until 2004. In 2004, former Minister of Citizenship and Immigration Judy Sgro resigned amid accusations that she had granted a visa extension to a Romanian exotic dancer who had worked on her election campaign. Even though Ms. Sgro was cleared of all conflict-of-interest allegations by the then Ethics Commissioner, the damage to the abased exotic dancer visa had already been done (Barnett, 2007, p. 5). The policy allowing the fast tracking of visas for foreign exotic dancers was abolished in December 2004, when the Department of Human Resources and Social Development Canada rescinded its positive employment authorization of the exotic dance industry. From that point on, applications submitted by foreign women were processed on a case-by-case basis (Barnett, 2007, p. 5-6).

The process for obtaining an exotic dancer visa was now, in theory, equal to that of any other occupation within the temporary foreign worker program. Immigration officials working at Canadian foreign missions required applicants for the exotic dancer visa to present a valid work contract. The officials then verified that the employer was legitimate. They were also trained to detect and screen out applicants who came across as potential 'victims of trafficking.' The officials also applied health and security criteria and ensured that arrangements were made for the applicants to return to their country of origin once the work permit had expired (Barnett, 2007, p. 5-6). In other words, unlike they were doing before, the Canadian government could now conduct assessments on migrant sex worker's places of employment, prevailing wage rate, working conditions and demand for their services. Thus, the government would now have an opportunity to ameliorate unfavourable working conditions in the strip clubs and ensure that migrant women could continue to work in hazard-free and violence-free environments (Timoshkina and McDonald, 2011, p. 20). In actuality however, the enforcement of the employment authorization vastly curtailed the amount of exotic dancer visas issued to foreign 
women and provided no work related remedies for the migrants in the exotic dance industry in particular or the Canadian sex trade in general.

In 2005 there were fewer than 10 new exotic dancer visas issued to foreign women, down 82 percent from the 57 handed out just the year before. Permit extensions for migrant sex workers already in Canada also plummeted from 366 granted in 2004 to 60 in 2005 . According to a briefing book prepared in February 2006 for then Conservative Immigration Minister Monte Solberg, the permits were being rejected due to questionable job offers from potential employers (Gordon, 2006). Akin to the policies prescribed by the global anti-trafficking crusade, foreign women were again being denied the legal opportunity to migrate to Canada for their own 'protection.' Yet nothing was done to reform the industry from which they were being protected. To start with, the work permits issued to migrant sex workers continued to tie them to one employer, making them unable to legally work anywhere else but the club that had hired them. For this reason, most were reluctant to complain even when their working conditions were poor or exploitative (Timoshkina, McDonald, and Wellesley Institute, 2009, p. 35). Migrant sex workers were also unlikely to file complaints because most often they were unaware of their rights and of club owners' responsibilities. Frequently migrant women simply tolerated the existing conditions or took personal responsibility to develop strategies to protect themselves, because moving to clubs with better conditions was prohibited unless a migrant sex worker was willing to go through the process of obtaining another work permit at the cost of being rejected and sent home (STAR, 2004, p. 21). However, even if a migrant sex worker did manage to file a complaint, in Canada it is the provinces that have jurisdiction over workers' employment rights under the Constitution. Since most provincial standard regimes are complaint-based systems (like the exotic dance industry), a lack of proactive provincial monitoring and enforcement 
exacerbates existing power differentials between employers and migrant workers. This effectively prevents migrant workers from accessing the system altogether. Moreover, even where workers intend to follow through on claims to vindicate their rights, they are normally back in their home countries before their cases are adjudicated and as a result, are cut off from effective remedies (STAR, 2004, p. 21, Nakache and Kinoshita, 2010, p. 8, Baxter, 2010, p. 12). The complaint-based system and lack of proactive monitoring allowed the conditions that threatened the health and safety of migrant sex workers, and to some extent Canadian sex workers, to continue without improvement in some clubs (STAR, 2004, p. 21).

Since sex trafficking to Canada has been mainly associated with the recruitment of foreign women by agents or brokers for work in strip clubs and massage parlors, the Canadian government seems to think that limiting access to the sex trade will prevent human trafficking. However, in their study of sex worker service providers, Timoshkina, McDonald, and the Wellesley Institute found more complex scenarios of trafficking occurring in Canada. Specifically, several service providers reported dealing with a growing number of family (or familial) trafficking cases, where young women were brought to Canada on visitor visas or student visas by relatives for the purpose of "helping out" with housekeeping and babysitting, and then forced to provide sexual services to single male relatives, friends, and/or strangers (Timoshkina, McDonald, and Wellesley Institute, 2009, p. 23). Thus, attempting to eradicate the sex industry in a bid to prevent the harm of trafficking is an unworkable solution, as not all victims of trafficking are sex workers nor have all sex workers been trafficked (Sanghera, 2012, p. 11, Kapur, 2003).

At this point if Canada truly wanted to 'protect' the migrant women working in the sex industry the government should have targeted the abuse, force labour, and violations of rights 
which the migrant women continued to endure under the hands of the Canadian business owners and other agents who facilitated their migration. However, it was being increasingly noted internationally that Canada's fight against trafficking was exasperatingly slow. Canada had also been heavily criticised by international experts, the United States, NGOs and human rights activists for its lackluster anti-trafficking policies and failure to implement adequate protection measures for trafficking victims (Timoshkina and McDonald, 2011, p. 6, De Shalit et al., 2014, p. 394). Furthermore, long-time exotic dancer visa program critic and New Democrat Member of Parliament Pat Martin stated that the government still wasn't going far enough and called for a total ban on work permits for foreign strippers, lest the government be branded a "pimp" (Gordon, 2006). In answer to these criticisms however, the 2007 legislation implemented in the name of further 'protecting' migrant women only served to further diminish their ability to migrate independently to Canada.

Introduced in the House of Commons on May 19, 2007, federal Bill C-57 aimed at further curtailing the exotic dancer visa program by giving immigration officers the right to deny temporary work visas to foreign women under the guise of 'protecting' them from being “trafficked" and "humiliated"(Barnett, 2007, p. 1, Timoshkina, McDonald, and Wellesley Institute, 2009, p. 33). In providing a rationale for this amendment, Minister of Citizenship and Immigration Diane Finley stated that she designed the bill to "protect vulnerable foreign workers, ones that could easily be exposed to sexual exploitation, harassment and abuse" (Barnett, 2007, p. 8, Wattie, 2007). Instead of providing migrant women with more opportunities to migrate legally and safely into hazard-free and violence-free environments, the Canadian government came one step closer to barring them from legally migrating through the exotic dancer visa all together (Timoshkina and McDonald, 2011, p. 20). Canada's anti-trafficking 
policies concerning "protecting vulnerable foreign workers" diverted attention away from the exploitative practices of employers and the unregulated sex industry, towards a law-and-order agenda of 'getting tough' with 'traffickers' and helping the vulnerable victims (Sharma, 2015). Closing the door to legal entry for migrant sex workers does not necessarily reduce the number of people migrating to Canada to work in the sex industry, nor does it diminish their vulnerability to exploitation throughout their migratory journey once in Canada (Macklin, 1999, p. 26). Indeed, women destined for the sex industry will continue to enter clandestinely or as visitors, refugee claimants, students, or domestic workers. At this point, although employers and agents who employ and exploit migrant women are also breaking the law, it is the women who are at greater risk because it is easier to 'rescue' and deport 'victims of trafficking' than to successfully prosecute Canadian business owners or agents under criminal or immigration legislation (Macklin, 2003, p. 484, p. 491). Nevertheless, migrant sex worker's illegality combined with the lack of enforcement of labour standards in the sex industry will continue to produce exploitation and situations of trafficking, until both issues are addressed in unison.

In an unexpected turn of events, the Adult Entertainment Association of Canada (AEAC), an organization representing 53 of the 140 clubs in Ontario, publically announced that the situation in the clubs - at least those belonging to the AEAC - had improved significantly since the end of the 1990s. The AEAC maintained that the business had cleaned itself up, illegal sexual acts in the clubs were absolutely forbidden, working conditions met all required labour standards and regulations, foreign women were now receiving hourly wages ( $\$ 12 /$ hour) plus tips, and were provided with information about their rights, obligations, health care, etc. (in English, Hungarian, Romanian, and Spanish) (Timoshkina, McDonald, and Wellesley Institute, 2009, p. 34). Additionally, Tim Lambrinos, the director of the AEAC, said the clubs his group represents are 
not in the business of exploiting, humiliating, or degrading anyone. Lambrinos further stated that "nobody in the industry condones degradation and abuse, and we're suggesting several ways of addressing (Ottawa's) concerns" (Wattie, 2007). The recommendations proposed by the AEAC included barring agents from applying for work permits on behalf of migrant women, a toll-free tip line to report abuse, allowing migrant sex workers to be eligible for re-entry visas, issuing standardized contracts between employer and employee, and allowing them to work only in accredited facilities. Therefore, the AEAC actually proposed more active monitoring of the industry, supposedly in the interest of protecting workers and cleaning up the industry's reputation (Wattie, 2007, Macklin, 2003, p. 489). Regrettably, these recommendations were never established, thus unsurprisingly, rather than directly addressing the conditions associated with potential exploitation in the sex industry, the Canadian government decided to completely eliminate the sex trade from the temporary foreign worker program.

On July 14, 2012 Ministerial Instructions were established for Work Permit Applications submitted from both within and outside of Canada. The instructions stated that "applications from foreign nationals seeking to work for an employer that is in a sector where there are reasonable grounds to suspect a risk of sexual exploitation of some workers are not to be processed." As per the Ministerial Instructions, strip club, massage parlours, and escort services are considered businesses where there are reasonable grounds to suspect a risk of sexual exploitation. As a result, these instructions applied to all work permit applications where the applicant is destined to work in one of these businesses, irrespective of the specific occupation that the applicant is intended to fill at the business (Government of Canada, 2012a). For instance, even if a foreign worker were applying for a kitchen position in a strip club, as a cook or dishwasher, etc., they would be refused on the basis of 'protecting' them against possible sexual 
exploitation. At the same time, migrant women currently in Canada on an exotic dancer visa were no longer eligible to have their work permits renewed and either had to leave the country or continue living in Canada illegally. In addition, as per subsection 185 (b) of the Immigration and Refugee Protection Regulations, all open work permits have the following condition placed: Not valid for employment in businesses related to the sex trade such as strip clubs, massage parlours, or escort services. According to the government of Canada, this condition informs the work permit holder that employment, self-employment, or contract services in this sector are not permissible (Government of Canada, 2012a). These Ministerial Instructions succeeded in not only terminating what was left of the exotic dancer visa but eliminated legal access to the sex industry for migrant workers altogether.

Canada has justified the migrant sex worker ban by declaring that, "foreign nationals brought to Canada to work in sex trade related businesses are particularly at risk of being exploited or abused. Denying these businesses access to temporary foreign workers will help protect vulnerable individuals by keeping them out of these types of situations" (Government of Canada, 2012b). Denying migrants access to the sex industry is also aligned with Canada's recently adopted view that "prostitution victimizes the vulnerable and that demand for sexual services can be a contributing cause of human trafficking” (Government of Canada, 2012, p. 11). Thus, following in the steps of global anti-trafficking discourses, the Canadian government has exclusively attached trafficking to prostitution and implemented a restrictive policy framework in the name of 'protecting' migrant sex workers from potential sexual exploitation. Adding to this globally prescribed anti-trafficking rhetoric, speaking to the implementation of the migrant sex worker ban, former Minister of Citizenship and Immigration Jason Kenney publically announced: 
These changes reflect our Government's ongoing commitment to strengthen partnerships and collaboration to prevent and combat the crime, the odious crime, of human trafficking, often described as modern-day slavery. I think we could all agree that Canada's immigration system should not be used or abused to exploit vulnerable people. Supporting businesses that pose these risks of exploitation is clearly not a good use of Canada's immigration system or its resources (Government of Canada, 2012c).

The Canadian government's logic for prohibiting the sex trade from the temporary foreign worker program is significantly flawed. Canada's sex trade is not the only industry within the temporary foreign worker program that has been accused of abusing and exploiting its migrant workers. Indeed, the low-skilled stream of the TFWP has been reporting instances of labour abuse and exploitation for years due to similar issues such as, the absence in enforcement of labour regulations, precarious immigration status, and lack of employment mobility all causing unchecked abuse and exploitation (Nakache and Kinoshita, 2010, p. 30, Faraday, 2012, p. 25, Cundal and Seaman, 2012, p. 206). Yet instead of having this program also prohibited from the TFWP for its ability to be 'used and abused to exploit vulnerable people,' the Canadian government moved to enhance its information and awareness material for the TFWP and improve the programs through policy initiatives including, internal detection and prevention protocols to identify high-risk employers, and policy development for on-site employer visits (Government of Canada, 2012, p. 15-16). As the next section argues, these program improvements should have also been implemented to the exotic dancer visa program as a way of addressing the abuse and exploitation taking place, instead of completely prohibiting the sex trade from accessing the temporary foreign worker program for migrant sex worker's 'protection.' 


\section{CHAPTER IV}

\section{A COMPARATIVE ANALYSIS: EVALUATING THE EXOTIC DANCER VISA PROGRAM AGAINST THE LOW-SKILLED STREAM OF THE TFWP}

\section{Sex Industry Standards and Labour Protections for Low-Skilled Workers: a Case Against Canada's Migrant Sex Worker Ban}

A hallmark of the Canadian TFWP is that it is a bifurcated system with two formalized streams: one targeted at highly skilled workers (NOC 0, A, and B), and the other targeted at lowskilled workers (NOC C and D) in accordance with the National Occupational Classification (NOC) (Hari, McGrath and Preston, 2013, p. 18). The jobs filled by low-skilled TFWs are frequently at least one of the "3D's" 'dirty, dangerous, and demanding' and in some cases all three. As previously discussed, migrants are often motivated to take these 'undesirable' jobs because the living conditions in their home country make them the best, and sometimes the only, way to provide for themselves and their families (Lenard and Straehle, 2010, p. 283). Consequently, within the TFWP, the greatest proportionate growth has been among low-skilled, low-waged workers (Faraday, 2012, p. 11). This rapid growth has been largely employer-driven and despite the need for TFWs on an ongoing basis, temporary labour migration remains structured in Canadian immigration law as a "temporary" phenomenon (Faraday, 2012, p. 11, Nakache and D'Aoust, 2012, p. 158). For example, according to the 2014 Annual Report to Parliament on Immigration: "the TFW Program is intended to ensure that it is only used as a last and limited resort to fill acute labour shortages on a temporary basis when qualified Canadians and permanent residents are not available" (p. 16). This, however, is in theory. In practice, TFWs are admitted temporarily to do jobs that Canadians and permanent residents will not (as opposed to cannot) do under dismal prevailing wages and working conditions. Thus, in political terms, immigrants are admitted to Canada as parties to an ongoing, open-ended and theoretically 
renegotiable social contract; temporary workers on the other hand, enter as mere parties to private non-negotiable employment contracts. The end of the work relationship signals the end of the worker's relationship with Canada. Temporary workers thus have a place in the economy, but not the nation (Macklin, 2003, p. 466).

Temporary status often means precarious well-being and differential treatment concerning social inclusion and exclusion. From this perspective, temporary foreign worker programs can be seen as contributing to the long-term presence of resident workers with unequal and precarious status (Goldring, 2010, p. 53). To illustrate this unequal treatment, work permits in the TFWP specify the location, the occupation, and the employer for whom the TFW can work, thereby restricting the workers' labour mobility (Barnetson and Foster, 2013, p. 351). Consequently, many TFWs experience heightened labour insecurity characterized by limited social benefits and statutory entitlements, job insecurity, low wages, and high risk of ill health. At the same time, limited mobility compounds the effects of other common characteristics of migrant workers such as, limited knowledge of the laws, institutions, and labour market, language barriers, limited financial resources, and makes migrant workers vulnerable to exploitation by their employers or labour brokers, including unpaid wages, dangerous work, and inadequate housing (Barnetson and Foster, 2013, p. 352, p. 351). For these reasons, it is argued that TFW programs create an entire stratum of vulnerable workers. These are workers who typically have no right to switch employers or jobs and whose stay in Canada depends solely on the employer being satisfied with their work conduct and performance. Further, these workers are often socially isolated during their stay and must leave the country when their work permits expire (Siemiatycki, 2010, p. 62). 
The administration of the TFWP is also complex and confusing, adding to the vulnerability of migrant workers. According to the Constitution Act, 1867, immigration is a matter of shared federal-provincial jurisdiction. The Parliament of Canada may make laws with respect to "aliens," "unemployment insurance" and "criminal law," whereas "civil rights" are under the authority of provincial legislatures. This means that provinces govern for example, employment rights, health care, education and housing. Thus, while the federal government regulates the entry and stay of migrant workers, many of their protections are covered by provincial laws. As the TFWP falls under the jurisdiction of both the federal and provincial governments, each of these players is somewhat restricted in its ability to resolve various challenges within the program. For example, the provinces' power to legislate work-related protections is limited by federal restrictions on temporary foreign workers. Moreover, while the federal government might be better equipped to protect such workers from exploitation, it is the provinces that have jurisdiction over the worker's employment rights under the Constitution. All this makes it hard even for legal experts to navigate through the appropriate channels (Nakache and Kinoshita, 2010, p. 8).

While in Canada, temporary foreign workers have the same rights and protections as Canadian workers under applicable federal/provincial/territorial employment standards and occupational health and safety laws (ESDC, 2014, p. 25). However, an overall lack in legislation requiring provincial governments to monitor the working conditions provided by employers who hire TFWs made it easier for employers to ignore employment standards and occupational health and safety (Cundal and Seaman, 2012, p. 211-212). Identical to what occurred for migrant sex workers within the exotic dancer industry. At the same time, another area of concern for all TFWs is reports of unscrupulous immigration consultants or employment 'brokers' charging 
recruitment fees to migrant workers. While Canadian laws prohibit an agency from charging recruitment fees to the migrant worker, these laws are unenforceable outside of Canada thus creating a situation where workers may be charged recruitment fees amounting to thousands of dollars. Furthermore, once in Canada recruitment fees are often deducted from wages of the workers thus, dramatically lowing a worker's wages (Cundal and Seaman, 2012, p. 211, p. 204). As previously discussed, this is a situation that migrant sex workers also faced when employed in Canada's sex industry. Often however, it would also be strip club owners charging recruitment fees. As these employers were not overseas but in Canada, the laws prohibiting the charging of recruitment fees could and should have been enforced for sex industry employers as a way to address the issues concerning the exploitation of migrant sex workers as opposed to eliminating the program altogether. Nevertheless, the employer-specific nature of the contemporary TFWP exposed all low-skilled migrant workers, regardless of industry, to exploitative and abusive working conditions (Hari, McGrath and Preston, 2013, p. 19).

Since 2010, Citizenship and Immigration Canada and Human Resources and Skills Development Canada have taken steps to improve protections for temporary foreign workers and reinforce employer compliance with program requirements. In April 2011, regulatory changes were implemented to the broader Temporary Foreign Worker Program that, among other provisions, improved the assessment of job offer genuineness, and denied program access to employers who did not abide by the terms of their job offers. Even though at that time the exotic dancer visa program was still in effect, these protections were not afforded to the migrant women destined for Canada's sex industry. Thus, instead of reinforcing employer compliance with the TFW program requirements within the strip clubs, massage parlours, escort services, and other establishments of the Canadian sex trade, the government prohibited these businesses from 
accessing the TFWP altogether. In some provinces where foreign workers' situations have been studied in great detail, flagrant abuses of statutory employment protections were made evident on a broad scale. In Alberta, for example, $60 \%$ of restaurants employing foreign workers were found to have contravened that province's Employment Standards Code (Baxter, 2010, p. 11). Yet, instead of banning all the industries within the TFWP that had reported abuse, in the 2012 National Action Plan to Combat Human Trafficking, the Government of Canada condemned all forms of forced labour, including exploitation tied to human trafficking while announcing protections to foreign nationals beyond those in place under provincial and territorial laws (Government of Canada, 2012, p. 13). Some of these additional protections included Human Resources and Skills Development Canada developing awareness products for temporary foreign workers, employers, third parties, and Service Canada officers, while working with Citizenship and Immigration Canada to update and translate into five foreign languages a brochure informing temporary foreign workers of their rights and providing important contact information (Government of Canada, 2012, p. 12).

The changes implemented to the TFWP starting in 2010 apparently did not go far enough in terms of protecting migrant workers from exploitation and abuse. On June 20, 2014, after several months of more scandals and controversies surrounding the use, abuse, and maltreatment of TFWs, both the Employment Minister, Jason Kenney, and Citizenship and Immigration Minister, Chris Alexander, unveiled the transformed version of the TFWP. The new version divides the TFWP into two streams: i) TFWs in controlled occupations that require the issuance of a Labour Market Impact Assessment (LMIA) to be administered by Employment and Social Development Canada (ESDC) and ii) International Mobility Programs which are LMIA exempt and under control of Citizenship and Immigration Canada. According to EDSC, the changes to 
the TFWP are intended to return the foreign worker program to its original position, where it was utilized as the last and limited resource for employers (Ali, 2014, p. 13). The labour market test that allows employers to bring temporary foreign workers to Canada was transformed from a Labour Market Opinion (LMO) to the new Labour Market Impact Assessment (LMIA) process that is accordingly, more comprehensive and rigorous. Employers must provide additional information, including the number of Canadians that applied for their available job, the number of Canadians the employer interviewed, and explain why those Canadians were not hired. Had this change been implemented for the exotic dancer visa, employers would have had to explain why so few Canadian women were willing to work in this industry (ESDC, 2014, p. 9). This would have possibly allowed for a much-needed examination of the work expectations, working conditions, and lack of labour standards enforcement, which kept Canadian women from working in this part of the sex industry.

With the changes implemented in 2014, the government of Canada also introduced a cap to limit the proportion of low-waged temporary foreign workers that a business can employ. According to these new regulations, employers with 10 or more employees applying for a new LMIA are subjected to a cap of 10 percent on the proportion of their work force that can consist of low-waged TFWs. This cap is applied per worksite of an employer and is based on total hours worked at that site. At the same time due to the concerns over the abuse of TFWs, the government also massively increased the number of inspections so that one in four employers using foreign workers will be inspected each year. These inspections are to be the result of tips, employers being deemed high-risk and random audits (EDSC, 2014, p. 10, p. 17). The Canadian government also significantly increased the scope of its inspections. In the past inspectors were only able to review whether employers were compliant with 3 of 21 program requirements. Since 
December 31, 2013 however, inspector can review all 21 program requirements when conducting their inspections. Some of these additional requirements include whether the employer: i) are in compliance with federal and provincial/territorial laws that regulate employment and recruitment in the province/territory in which the foreign worker is employed; ii) have made reasonable efforts to provide a workplace that is free of abuse which includes: physical abuse, sexual abuse, psychological abuse, and financial abuse; and iii) have provided accurate information in the context of an LMIA application. This means that if employers are found to have provided false or misleading information on any part of the LMIA application they will be found non-compliant (ESDC, 2014, p. 18-19).

These policy initiatives could have also been used within the sex industry as a way of addressing the abuse and exploitation that migrant women were subjected to. As one of the main problems with the use exotic dancer visa was that employers and immigration 'brokers' were misusing it to import large quantities of foreign women, the cap limiting the amount of lowwaged workers a business can employ would have potentially thwarted the malignant overuse of the visa. Likewise, since the employers of the sex industry were hardly in receipt of regular inspections before the sex worker ban, the increase in the number of inspections could have possibly increased employer compliance with TFW program requirements and eliminated the amount of abuse and exploitation taking place in the sex industry. Although the use of the cap would possibly mean that less migrant women would have the chance to legally migrate to Canada, it still leaves an open opportunity for women to not have to travel clandestinely, migrate safely, and work in hazard-free and violence-free environments (Timoshkina and McDonald, 2011, p. 20). 
With the new policy improvements implemented for the TFWP in 2014, the government of Canada also launched a Confidential Tip Line for Canadians to report abuse of the Temporary Foreign Worker Program. In addition to the tip line, a new Complaints Web page has been launched to allow the public to submit tips easily and securely online. According to ESDC, the government of Canada "will continue to follow up on each and every complaint to make sure that employers who break the rules are caught and face the consequences" (ESDC, 2014, p. 19). The federal government is also taking steps to significantly improve the level of information sharing between different levels of government. As previously discussed, the shared responsibility of the TFWP between federal and provincial governments made the administration of the program problematic. Thus, the benefits for foreign workers deriving from this information sharing agreement between the federal government and the provinces and territories are clear. For example, employers who violate provincial labour laws, health and safety standards, or recruiting laws will face greater scrutiny and oversight from the TFWP and would be considered "high-risk employers." Likewise, the federal government will share information with the provinces and territories on employers who break the rules of the TFWP in order to allow provinces and territories to follow up and prioritize their investigations on matters, namely labour laws and health and safety standards (EDSC, 2014, p. 21). Each one of these policy initiatives should have also been applied to the exotic dancer visa and the sex trade as a way of mitigating the recurring abuse and exploitation, while providing migrant women with an opportunity for legal migration. In eliminating the sex trade from the TFWP, the government of Canada joined the global anti-trafficking movement in the common-but unjustifiedassumption that "labour trafficking" and "sex trafficking" are distinct and different species of harm. However this distinction does not reflect the complex reality of migrant women's 
experiences within the sex industry. Instead of proposals to criminalize industries where incidences of forced labour and abuse have been identifies (such as the low-skilled stream of the TFWP), strategies to prevent labour trafficking tend to focus on improving the substandard working conditions, like in the case of Canada. The time has come to apply this logic and link anti-trafficking efforts with initiatives aimed at improving the working conditions of workers in the sex industry (Simmons and David, 2012, p. 63, p. 77).

Most of these newly implemented protections initiated for the TFWP were also suggested for the exotic dancer visa program before its elimination. For instance the McDonald et al., (2002) study on migrant sex workers made several recommendations concerning the Canadian sex trade and the preventative and interventionist efforts that must be taken in order to achieve effective outcomes for migrant women. The study recommended that materials pertaining to Canadian laws should be distributed at ports of entry, to all temporary workers, visitors, and students. The authors suggested that the information should be made available in foreign languages (McDonald et al., 2002, p. 66). This is not far from what the Canadian government proposed to implement in 2012, only the sex trade was excluded from these much-needed program modifications. The study also recommended the development of a neutral, regulated, governing body mandated to oversee the strip clubs and massage parlours during hours of operation to ensure that the rules remain stable (McDonald et al., 2002, p. 67). This governing body could have helped to improve employer compliance with TFW program requirements, similar to what the Canadian government enforced for the rest of the TFWP in 2010. Furthermore, as previously discussed, the Adult Entertainment Association of Canada (AEAC) proposed a toll-free tip line to report abuse taking place within the exotic dance industry (Wattie, 2007). The government of Canada did not bother to initiate any of these program 
recommendations or try in any way to improve the working conditions of migrant sex workers by including the exotic dancer visa in the TFW program restructuring. Instead the Canadian government eliminated a legal opportunity for foreign women to migrate to Canada while rhetorically broadcasting that it was for their 'protection.'

There were also a number of issues related to the administration of the program itself, which were never addressed or resolved. For instance, The Timoshkina, McDonald and Wellesley Institute (2009) study on sex worker service providers also noted that migrant women did not have access to education and language training, and had no avenues for becoming landed immigrants in Canada, aside from marrying Canadian men they met in strip clubs. However, the study also reports that migrant women who married their customers often fell victim to domestic violence (p. 35). It is interesting to note that at no point in the evolution of the exotic dancer visa policy responses did the government or employers contemplate that the solution to the shortage of Canadian strippers would be to facilitate the permanent immigration of qualified and experienced foreign exotic dancers. Here the silence of government officials and club owners alike conveys the shared but unarticulated consensus that these women were not suitable candidates for future Canadian citizens. At the same time, the granting of permanent residence would have defeated the club owners' interest in retaining a pool of women who had no legal option but to work for them (Macklin, 2003, p. 481). Granting permanent residency to migrant sex workers would have meant accrediting the sex trade, and more specifically the exotic dance industry, as an economic necessity as opposed to a internationally agreed upon conduit for sexual exploitation and human trafficking.

The Timoshkina, McDonald and Wellesley Institute (2009) study on sex worker service providers also reported that the development of exit, transitional, or career change programs was 
identified as one of the top programming priorities. Here the service providers reiterated that the majority of individuals are in the sex trade out of economic necessity and do not intend to stay forever, and that even those who like to work have to eventually move on to something else, since the industry favours younger workers. Yet exit programs for sex workers are virtually nonexistent. The authors note that this is a "cruel irony considering that the trade is criminalized and stigmatized, and that the popular public sentiment seems to be that sex worker should get "honest jobs' and do 'something better' with their lives." According to the authors, the few known exit programs are very basic and geared towards female sex workers who are poor and confined to the lower echelons of the sex industry (e.g., street prostitution). Therefore, such programs are not suitable for many migrant sex workers who are highly educated, and do not guarantee adequate income for those who are used to making a good living in the sex trade. In this study, service providers recommended exit programs to be comprehensive comprising educational components, vocational and professional training, life skills counselling, as well as motivational pubic speaking, and mentoring by former sex workers who have built successful careers after leaving the sex industry (Timoshkina, McDonald and Wellesley Institute, 2009, p. 50). In implementing the migrant sex worker ban, these much needed exit strategies for migrant sex workers were completely disregarded in favour of combating human trafficking through rescue-driven responses aimed at the 'victims' of the sex trade. This is part of the broad and continuing instance where the Canadian government should have addressed the exploitation occurring within the sex industry through appropriately recommended policy initiatives as opposed to prohibiting migrants from legally accessing the sex industry as part of their anti-trafficking campaign. 


\section{CONCLUSION}

This study has argued that the influential definition of what constitutes trafficking fails to account for the reality of the current worldwide crisis of displacement, the intensified expansion of global capitalist markets over the last quarter century and the proliferation of ever increasing restrictive immigration policies that prevent the majority of migrants, especially women, from ever realizing full status in the countries and labour markets they migrate to (Sharma, 2003, p. 54). At the same time, the internationally accepted definition of human trafficking emphasizes trafficking as a form of transnational crime, resulting in counter-trafficking initiatives that focus on restrictive border, and immigration policies (Kaye, Winterdyk, and Quarterman, 2014, p. 2425). For this reason, global anti-trafficking policies do a great disservice to migrant women. By diverting attention away from the practices of nation states and employers, they channel support towards a law-and-order agenda of 'getting tough' with 'traffickers' and rescuing the 'victims of trafficking' (Sharma, 2015). Thus, instead of 'protecting' migrant women, anti-trafficking policies only serve to victimize them further and strip them of their agency, while driving women

deeper into clandestine channels of migration that provide the groundwork for further uncontested exploitation.

According to the Canadian government, the 2012 Ministerial Instructions prohibiting the Canadian sex industry from accessing the temporary foreign worker program was implemented for the 'protection of vulnerable individuals' from the risk of sexual exploitation and human trafficking (Government of Canada, 2012c). In implementing the migrant sex worker ban the Canadian government reaffirmed its commitment to the global anti-trafficking movement while exclusively attaching trafficking to prostitution and establishing a restrictive policy framework 
which limited foreign women's' migration options. However, prohibiting migrant women from legally accessing the Canadian sex trade is an ineffective mechanism for combating human trafficking.

Instead, this study has argued that providing feasible rights-based solutions (e.g., labour rights, immigration rights, and sexual rights) for mitigating the vulnerability and exploitation currently experienced by migrant women, and made worse by the global anti-sex work crusade, is tantamount to ensuring their safety and security during both the migration process and once they have arrived in the country of destination (Lerum et al., 2012, p. 100). This follows that the only way to truly end practices of exploitation, to make migration safer, and to end the conditions that make migrant women, especially migrant sex workers vulnerable in all areas of their lives, is to begin from the standpoint that women migrants have some agency, even with limited options (Sharma, 2003, p. 62). This means examining the root causes of women's crossborder movements and understanding that women are making decisions to create a better life for themselves and their families within a realm of limited possibilities for employment (Lepp, 2002, p. 6, O'Brien, Carpenter and Hayes, 2013, p. 412, McDonald, Moore and Timoshkina, 2002, p. 45). This perspective positions migrant sex workers as rights-bearing individuals who deserve genuine protection against exploitation, not through the elimination of their employment in the sex industry. Instead using a proposed rights-based approach where: women are provided with safe channels for migration; labour laws are implemented for their protection as workers; and a women's right to choose to work in the sex industry is upheld. 


\section{REFERENCES}

Agustín, L. M. (2005). "Migrants in the Mistress's House: Other Voices in the "Trafficking" Debate." Social Politics: International Studies in Gender, State and Society, 12(1), 96-117.

Agustín, L. M. (2006). “The Disappearing of a Migration Category: Migrants Who Sell Sex.” Journal of Ethnic and Migration Studies, 32 (1), 29-47.

Agustín, L. M. (2007). Sex at the margins: migration, labour markets and the rescue industry. London, New York: Zed Books.

Ahmed, Aziza., \& Seshu, Meena. (2012). “We Have the Right Not to be 'Rescued'...”: When Anti-Trafficking Programmes Undermine the Health and Well-Being of Sex Workers." AntiTrafficking Review, issue 2, pp. 149-165.

Ali, Lotf Ali Jan. (2014). Welcome to Canada? A Critical Review and Assessment of Canada's Fast-Changing Immigration Policies. RCIS Working Paper No. 2014/6. Retrieved March 13, 2015, from, http://www.ryerson.ca/rcis/publications/rcisworkingpapers/

Alvarez, M., \& Alessi, E. (2012). "Human Trafficking is More than Sex Trafficking and Prostitution: Implications for Social Work.” Affilia, 27(2), 142-152.

Aradau, C. (2003). Trafficking in Women: Human Rights or Human Risks? Canadian Woman Studies, 22(3/4), 1-10.

Avendaño, A., \& Fanning, C. (2013). "Immigration Policy Reform in the United States: Reframing the Enforcement Discourse to Fight Human Trafficking and Promote Shared Prosperity." Anti-Trafficking Review, issue 2, pp. 97-118.

Barnett, Laura. (2007, July 24). Bill C-57: An Act to amend the Immigration and Refugee Protection Act. Retrieved from the Parliament of Canada website:

http://www.parl.gc.ca/About/Parliament/LegislativeSummaries/bills_ls.asp?ls=c57\&Parl=39\&Se $\mathrm{s}=1$

Barnetson, B., \& Foster, J. (2013). The Political Justification of Migrant Workers in Alberta, Canada. Journal of International Migration and Integration, 15(2), 349-370.

Barrett, Nicole., \& Shaw, Margaret. (2011). “Towards Human Trafficking Prevention: A Discussion Document." International Centre for Criminal Law Reform and Criminal Justice Policy. Retrieved March 25, 2015, from, http://www.crime-preventionintl.org/en/publications/publication/article/towards-human-trafficking-prevention-a-discussiondocument-1.html

Beran, K. (2012). "Revisiting the Prostitution Debate: Uniting Liberal and Radical Feminism in Pursuit of Policy Reform." Law and Inequality: A Journal of Theory and Practice, 30(1), 19. 
Baxter, J. (2010). Precarious Pathways: Evaluating the Provincial Nominee Programs in Canada: A Research Paper for the Law Commission of Ontario. Retrieved February 22, 2015, from, http://www.lco-cdo.org/baxter.pdf

Bertone, A. M. (1999). "Sexual Trafficking in Women: International Political Economy and the Politics of Sex." Gender Issues, 18(1), 4-22.

Brock, D. R. (1998). Making work, Making Trouble: Prostitution as a Social Problem. Toronto: University of Toronto Press.

Bruckert, Christine., \& Parent, Colette. (2002). "Trafficking in Human Beings and Organized Crime: A Literature Review." Research and Evaluation Branch Community, Contract and Aboriginal Policing Services Directorate Royal Canadian Mounted Police. Retrieved May 28, 2015, from, http://www.rcmp-grc.gc.ca/pubs/ccaps-spcca/traffick-eng.htm

Bruckert, Christine., \& Parent, Colette. (2004). "Organized Crime and Human Trafficking in Canada: Tracing Perceptions and Discourses." Research and Evaluation Branch Community, Contract and Aboriginal Policing Services Directorate Royal Canadian Mounted Police.

Retrieved May 14, 2015, from, http://www.rcmp-grc.gc.ca/pubs/ccaps-spcca/oc-co-hum-eng.htm

Citizenship and Immigration Canada. (2014, May 28). Temporary Foreign Worker Program and International Mobility Program: Protecting Workers from Abuse and Exploitation. Retrieved March 24, 2015, from, http://www.cic.gc.ca/english/resources/tools/temp/work/vulnerable.asp

Cohen, S. (1972). Folk Devils and Moral Panics: The Creation of the Mods and Rockers. MacGibbon \& Kee.

Cundal, K., \& Seaman, B. (2012). “Canada's Temporary Foreign Worker Programme: A Discussion of Human Rights Issues.” Migration Letters, 9(3), 201-214.

Davidson O’Connell, Julia. (2002). "The Rights and Wrongs of Prostitution." Hypatia, 17(2), 84-98.

De Shalit, A., Heynen, R., \& van der Meulen, E. (2014). "Human Trafficking and Media Myths: Federal Funding, Communication Strategies, and Canadian Anti-Trafficking Programs." Canadian Journal Of Communication, 39(3), 385-412.

Department of Justice Canada. (2015, February 16). A Handbook for Criminal Justice Practitioners on Trafficking in Persons. Retrieved May 22, 2015, from, http://www.justice.gc.ca/eng/rp-pr/cj-jp/tp/hcjpotp-gtpupjp/index.html

Dobrowolsky, A. (2011). The Intended and Unintended Effects of a New Immigration Strategy: Insights from Nova Scotia's Provincial Nominee Program. Studies in Political Economy, 87, 109-141. 
Doezema, Jo. (2000). "Loose Women or Lost Women? The Emergence of the Myth of White Slavery in Contemporary Discourses of Trafficking in Women." Gender Issues, 18 (1) 23-50.

Doezema, J. (2010). Sex Slaves and Discourse Masters : The Construction of Trafficking. London: Zed Books.

Dottridge, Mike. (2007). "Introduction.” In Collateral Damage: The Impact of Anti-Trafficking Measures on Human Rights Around the World. Global Alliance Against Traffic in Women (GAATW). Retrieved May 25, 2015, from, http://www.gaatw.org/Collateral\%20Damage_Final/singlefile_CollateralDamagefinal

Employment and Social Development Canada (ESDC). (2014). Overhauling the Temporary Foreign Worker Program I ESDC. Retrieved June 18, 2015, from, http://www.esdc.gc.ca/eng/jobs/foreign_workers/reform/overhauling_TFW.pdf

Faraday, F. (2012). Made in Canada: How the Law Constructs Migrant Workers' Insecurity. Toronto, Ont: Metcalf Foundation, [2012]. Retrieved February 22, 2015, from, http://metcalffoundation.com/publications-resources/view/made-in-canada/

Federici, S. (2006). "Prostitution and Globalization: Notes on a Feminist Debate." In Davies, M., \& Ryner, M. (Eds.). Poverty and the Production of World Politics: Unprotected Workers in the Global Political Economy. Palgrave Macmillan, 2006.

Fudge, J. (1991). "Reconceiving Employment Standards Legislation: Labour Law's Little Sister and the Feminization of Labour.” Journal of Law and Social Policy, 7, 73.

Fudge, J., \& MacPhail, F. (2009-2010). "Temporary Foreign Worker Program in Canada: LowSkilled Workers as an Extreme Form of Flexible Labor." Comparative Labor Law \& Policy Journal, 31(1), 5.

Global Alliance Against Traffic in Women (GAATW). (2010). "Beyond Borders: Exploring Links between Trafficking and Migration." GAATW Working Paper Series 2010. Retrieved May 2, 2015, from, http://www.gaatw.org/publications/WP_on_Migration.pdf

Global Alliance Against Traffic in Women (GAATW). (2010a). "Beyond Borders: Exploring Links between Trafficking and Gender." GAATW Working Paper Series 2010. Retrieved May 2, 2015, from, http://www.gaatw.org/publications/WP_on_Gender.pdf

Goldring, L. (2010). Temporary Worker Programs as Precarious Status. Canadian Issues, 50-54.

Gordon, J. (2006, May 26). Visa Changes Keeping Foreign Strippers Out: Fewer Dancers Granted Permits. Calgary Herald. Retrieved from, http://ezproxy.lib.ryerson.ca/login?url=http://search.proquest.com/docview/245391781?accounti $\mathrm{d}=13631$ 
Government of Canada. (2012). National Action Plan to Combat Human Trafficking. Retrieved March 20, 2015, from, http://www.publicsafety.gc.ca/cnt/rsrcs/pblctns/ntnl-ctn-pln-cmbt/indexeng.aspx

Government of Canada. (2012a, July 13). Operational Bulletin 449 - July 13, 2012. Retrieved March 4, 2015, from, http://www.cic.gc.ca/english/resources/manuals/bulletins/2012/ob449.asp

Government of Canada. (2012b, July 4). Canada News Centre - Archived - Government of Canada takes action to protect temporary foreign workers [News Releases]. Retrieved June 17, 2015, from, http://news.gc.ca/web/articleen.do?crtr.sj1D=\&crtr.mnthndVl=1\&mthd=advSrch\&crtr.dpt1D=420\&nid=684419\&crtr.lc1D= \&crtr.tp1D=1\&crtr.yrStrtVl=2008\&crtr.kw=\&crtr.dyStrtVl=26\&crtr.aud1D=\&crtr.mnthStrtVl= $2 \&$ crtr.page $=1 \&$ crtr.yrndVl=2015\&crtr.dyndVl=4\&_ga=1.175825632.336595593.1424307307

Government of Canada. (2012c, July 6). Speaking notes for The Honourable Jason Kenney, P.C., M.P. Minister of Citizenship, Immigration and Multiculturalism. Retrieved March 4, 2015 , from, http://www.cic.gc.ca/english/department/media/speeches/2012/2012-07-04.asp

Hari, A., McGrath, S., \& Preston, V. (2013). Temporariness in Canada: Establishing a Research Agenda. Toronto, ON, CAN: CERIS - The Ontario Metropolis Centre.

Huckerby, Jayne. (2007). "United States of America.” In Collateral Damage: The Impact of Anti-Trafficking Measures on Human Rights Around the World. Global Alliance Against Traffic in Women (GAATW). Retrieved May 25, 2015, from, http://www.gaatw.org/Collateral\%20Damage_Final/singlefile_CollateralDamagefinal

International Agreement for the Suppression of the White Slave Traffic, Paris, 18 July 1904, League of Nations, Treaty Series, vol. I, p. 83, available from, https://treaties.un.org/pages/ViewDetails.aspx?src=TREATY\&mtdsg_no=VII$8 \&$ chapter $=7 \&$ lang $=$ en

Jeffrey, Leslie Ann. (2005). "Canada and Migrant Sex Work: Challenging the 'Foreign' in Foreign Policy.” Canadian Foreign Policy Journal, 12 (1), p. 33-48.

Jeffreys, S. (2009). "Prostitution, Trafficking and Feminism: An Update on the Debate." Women's Studies International Forum, 32(4), 316-320.

Kapur, R. (2002) “The Tragedy of Victimization Rhetoric: Resurrecting the 'Native' Subject in International/Post-Colonial Feminist Legal Politics." Harvard Human Rights Journal, Spring, 137.

Kapur, R. (2003). The "Other" Side of Globalization: The Legal Regulation of Cross-Border Movements." Canadian Woman Studies, 22(3). 
Kapur, R. (2005). "Cross-border Movements and the Law: Renegotiating the Boundaries of Difference.” In Kempadoo, K., Sanghera, J., \& Pattanaik, B. (Eds.). Trafficking and Prostitution Reconsidered: New Perspectives on Migration, Sex work, and Human rights. Paradigm Publishers, 2005.

Kaye, J., Winterdyk, J., \& Quarterman, L. (2014). "Beyond Criminal Justice: A Case Study of Responding to Human Trafficking in Canada." Canadian Journal of Criminology and Criminal Justice, 56(1), 23-48.

Kempadoo, Kamala. (2005). "Victims and Agents of Crime: The New Crusade Against Trafficking.” In Julia Sudbury. (Eds.). Global Lockdown: Race, Gender, and the PrisonIndustrial Complex. New York and London: Routledge, 2005.

Kempadoo, Kamala (2005). "Introduction: Abolitionism, Criminal Justice, and Transnational Feminism. Twenty-First Century Perspectives on Human Trafficking.” In Kempadoo, K., Sanghera, J., \& Pattanaik, B. (Eds.). Trafficking and Prostitution Reconsidered: New Perspectives on Migration, Sex work, and Human rights. Paradigm Publishers, 2005.

Kissil, K., \& Davey, M. (2010). “The Prostitution Debate in Feminism: Current Trends, Policy and Clinical Issues Facing an Invisible Population." Journal of Feminist Family Therapy, 22(1), $1-21$.

Leidholdt, Dorchen. (2004). "Prostitution and Trafficking in Women: An Intimate Relationship." Journal of Trauma Practice, 2(3), 167-183.

Lenard, P. T., \& Straehle, C. (2010). Temporary Labour Migration: Exploitation, Tool of Development, or Both? Policy and Society, 29(4), 283-294.

Lepp, A. (2002). "Trafficking in Women and the Feminization of Migration: the Canadian Context." Canadian Woman Studies, 1-13.

Lerum, Kari., McCurtis, Kiesha., Saunders, Penelope., \& Wahab, Stephanie. (2012). “Using Human Rights to Hold the US Accountable for its Anti-Sex Trafficking Agenda: The Universal Periodic Review and New Directions for US policy." Anti-Trafficking Review, 2, 80-103.

Macklin, Audrey (1999). "Women as Migrants: Members in National and Global Communities." Canadian Woman Studies. (Fall) 19(3): 24-31.

Macklin, A. (2003). "Dancing Across Borders: 'Exotic Dancers,' Trafficking, and Canadian Immigration Policy.” International Migration Review, 37(2), 464-500.

March, Ian., \& Melville, Gaynor. (2011). Moral Panics and the British Media-A Look at Some Contemporary 'Folk Devils.' Internet Journal Of Criminology, 1-21. Retrieved January 22, 2016 from, http://www.internetjournalofcriminology.com/ijcarticles.html 
McDonald, L., Moore, B., \& Timoshkina, N. (2002, July 1). "Migrant Sex Workers from Eastern Europe and the Former Soviet Union: The Canadian Case." Retrieved from the Government of Canada Publications website: http://publications.gc.ca/site/eng/293561/publication.html

Metropolitan Action Committee on Violence Against Women and Children (METRAC). (2008). “Exotic Dancers Experiencing Workplace Sexual Violence and Harassment." METRC'S Workplace Justice Series. Retrieved June 23, 2015, from, http://www.owjn.org/owjn_2009/Images/pdfs/Exotic\%20Dancers.pdf

Miller, R., \& Baumeister, S. (2013). "Managing Migration: Is Border Control Fundamental to Anti-Trafficking and Anti-Smuggling Interventions?” Anti-Trafficking Review, 2, 15-32.

Nakache, D. (2010). “Temporary Workers: Permanent Rights?” Canadian Issues, 45-49.

Nakache, D., \& D’Aoust, S. (2012). "Provincial/Territorial Nominee Programs: An Avenue to Permanent Residency for Low- Skilled Temporary Foreign Workers?" In P.T. Lenard and C. Straehle. (Eds.). Legislated Inequality: Temporary Labour Migration in Canada. Montreal and Kingston: McGill-Queen's University Press.

Nakache, D., \& Kinoshita, P. J. (2010). "The Canadian Temporary Foreign Worker Program: Do Short-Term Economic Needs Prevail over Human Rights Concerns?.” Montreal, QC, CAN: Institute for Research on Public Policy.

O’Connell Davidson, Julia. (2006). "Will the Real Sex Slave Please Stand Up?" Feminist Review, 83, 4-22.

O'Connell Davidson, Julia. (2010). "New Slavery, Old Binaries: Human Trafficking and the Borders of Freedom.” Global Networks-A Journal of Transnational Affairs, 10(2), 244-261.

O’Brien, E., Carpenter, B., \& Hayes, S. (2013). "Sex Trafficking and Moral Harm: Politicised Understandings and Depictions of the Trafficked Experience.” Critical Criminology, 21(4), 401415.

Oxman-Martinez, J., Hanley, J., \& Gomez, F. (2005). "Canadian Policy on Human Trafficking: A Four-year Analysis.” International Migration, 43(4), 7-29.

Oxman-Martinez, J., Martinez, A., \& Hanley, J. (2001). “Trafficking Women: Gendered Impacts of Canadian Immigration Policies." Journal of International Migration and Integration / Revue de L'integration et de La Migration Internationale, 2(3), 297-313.

Protocol to Prevent, Suppress and Punish Trafficking in Persons, Especially Women and Children, Supplementing the United Nations Convention Against Transnational Organized Crime, New York, 15 November 2000, United Nations, Treaty Series, vol. 2237, p. 319; Doc. A/55/383, available from, https://www.unodc.org/unodc/treaties/CTOC/ 
Public Safety Canada. (2013). National Action Plan to Combat Human Trafficking - 2012-2013 Annual Report on Progress. (2014, March 4). Retrieved April 3, 2015, from, http://www.publicsafety.gc.ca/cnt/rsrcs/pblctns/2013-ntnl-ctn-pln-cmbt-hmn/index-eng.aspx

Public Safety Canada. (2013a). 2012-2013 Human Trafficking Stakeholder Consultations National Summary Report. Retrieved April 3, 2015, from, http://www.publicsafety.gc.ca/cnt/rsrcs/pblctns/2013-hmn-trffckng-stkhldr/index-eng.aspx

Root, Jesse., Gates-Gasse, Erika., Shields, John., \& Bauder, Harald. (2014). "Discounting Immigrant Families: Neoliberalism and the Framing of Canadian Immigration Policy Change." RCIS Working Paper no. 2014/7.

Roots, K. (2013). “Trafficking or Pimping?: An Analysis of Canada's Human Trafficking Legislation and its Implications." Canadian Journal of Law and Society, 28(1), 21-41.

Royal Canadian Mounted Police (RCMP). (2010, September 13). Human Trafficking in Canada: A Threat Assessment. Retrieved March 25, 2015, from, http://www.rcmp-grc.gc.ca/pubs/http/htta-tpem-eng.htm

Royal Canadian Mounted Police (RCMP). (2012). RCMP National Strategy to Combat Human Trafficking. Government of Canada Publications. Retrieved May 14, 2015, from, http://publications.gc.ca/site/eng/9.697062/publication.html

Sanghera, Jyoti. (2005). "Unpacking the Trafficking Discourse.” In Kempadoo, K., Sanghera, J., \& Pattanaik, B. (Eds.). Trafficking and Prostitution Reconsidered: New Perspectives on Migration, Sex work, and Human rights. Paradigm Publishers, 2005.

Schaeffer-Grabiel, F. (2010). "Sex Trafficking as the 'New Slave Trade'?” Sexualities, 13(2), 153-160.

Sex Trade Advocacy and Research (STAR) Project. (2004). Exotic dancing in Ontario: Health and safety. Retrieved June 23, 2015, from, http://web2.uwindsor.ca/courses/sociology/maticka/star/pdfs/exotic_dancing_in_ontario_final_re port.pdf

Sex Trade Advocacy and Research (STAR). (2006). Safety, Security and the Well-Being of Sex Workers: A Report Submitted to the House of Commons Subcommittee on Solicitation Laws (SSLR). Retrieved June 23, 2015, from, http://web2.uwindsor.ca/courses/sociology/maticka/star/pdfs/safety_and_security_report_final_v ersion.pdf

Sharma, Nandita. (2003). “Travel Agency: A Critique of Anti-Trafficking Campaigns.” Refuge, 21(3), 53-65. 
Sharma, Nandita. (2015). "Anti-Trafficking: Whitewash for Anti-Immigration Programmes." Open Democracy. Retrieved, April 07, 2015, retrieved from, https://www.opendemocracy.net/beyondslavery/nandita-sharma/antitrafficking-whitewash-forantiimmigration-programmes

Siemiatycki, M. (2010). Marginalizing Migrants: Canada's Rising Reliance on Temporary Foreign Workers. Canadian Issues, 60-63.

Sikka, Anette. (2013). Labour Trafficking in Canada: Indicators, Stakeholders, and Investigating Methods. Prepared for: Law Enforcement and Policing Branch, Public Safety Canada. Report NO. 42, 2013. Retrieved March 23, 2015, from, https://www.publicsafety.gc.ca/cnt/rsrcs/lbrr/ctlg/shwttls-eng.aspx?d=PS\&i=63310954

Simmons, Frances., \& David, Fiona. (2012). “The Road to Effective Remedies: Pragmatic Reasons for Treating Cases of "Sex Trafficking" in the Australian Sex Industry as a Form of "Labour Trafficking." Anti-Trafficking Review, 2, 60-79.

Soderlund, G. (2005). "Running from the Rescuers: New U.S. Crusades Against Sex Trafficking and the Rhetoric of Abolition." NWSA Journal, 17(3), 64-87.

Thobani, Sunera. (2001). "Benevolent State, Law-Breaking Smugglers, and Deportable and Expendable Women: An Analysis of the Canadian State's Strategy to Address Trafficking in Women.” Refuge, 19 (4), p. 24-33.

Timoshkina, N., McDonald, L., \& Wellesley Institute. (2009). "Building Partnerships for Service Provision to Migrant Sex Workers." Wellesley Institute. Retrieved May 18, 2015, from, http://www.wellesleyinstitute.com/wp-content/uploads/2011/11/Building-Partnerships-forService-Provision-to-Migrant-Sex-Workers.pdf

Timoshkina, N., \& McDonald, L. (2011). Sex Trafficking of Women to Canada: Results from a Qualitative Metasynthesis of Empirical Research. CERIS - The Ontario Metropolis Centre. Retrieved April 1, 2015, from, http://www.ceris.metropolis.net/wpcontent/uploads/pdf/research_policy/RFP/TimoshkinaMcDonald2009.pdf

Tomkinson, S. (2012). "The Multiplicity of Truths About Human Trafficking: Beyond "The Sex Slave” Discourse.” SSRN Scholarly Paper No. ID 2056287. Rochester, NY: Social Science Research Network. Retrieved May 14, 2015, from, http://papers.ssrn.com/sol3/papers.cfm?abstract_id=2056287

United Nations Office on Drugs and Crime (UNODC). (2008). Toolkit to Combat Trafficking in Persons. Retrieved May 14, 2015, from, http://www.unodc.org/unodc/en/humantrafficking/2008/electronic-toolkit/electronic-toolkit-to-combat-trafficking-in-persons--index.html 
United Nations Office on Drugs and Crime (UNODC). (2009). Global Report on Trafficking in Persons. Global Initiative to Fight Human Trafficking (UN. GIFT). Retrieved May 14, 2015, from, http://www.unodc.org/unodc/en/human-trafficking/global-report-on-trafficking-inpersons.html

United Nations Office on Drugs and Crime (UNODC). (2014). Global Report on Trafficking in Persons. United Nations publication, Sales No. E.14.V.10. Retrieved May 14, 2015, from, http://www.unodc.org/unodc/data-and-analysis/glotip.html

United States of America (U.S.) Department of State. (2014, June 19). Trafficking in Persons Report 2014. Retrieved April 27, 2015, from, http:/www.state.gov/j/tip/rls/tiprpt/2014/index.htm

Wattie, C. (2007, Aug 16). Exotic dancers protest immigration crackdown. CanWest News. Retrieved from, http://ezproxy.lib.ryerson.ca/login?url=http://search.proquest.com/docview/460123570?accounti $\mathrm{d}=13631$

2014 Annual Report to Parliament on Immigration. (2014, October 31). Government of Canada, Citizenship and Immigration Canada. Retrieved March 13, 2015, from, http://www.cic.gc.ca/english/resources/publications/annual-report-2014/index.asp 